\title{
NICKEL SPECIATION OF URBAN PARTICULATE MATTER
}

Final Report

For the period April 1, 2001, through September 30, 2002

Prepared for:

AAD Document Control

U.S. Department of Energy

National Energy Technology Laboratory

PO Box 10940, MS 921-107

Pittsburgh, PA 15236-0940

Cooperative Agreement No. DE-FC26-98FT40321

Performance Monitor: William Aljoe

Prepared by:

Kevin C. Galbreath Charlene R. Crocker Carolyn M. Nyberg

Frank E. Huggins Gerald P. Huffman

Energy \& Environmental Research Center University of North Dakota Box 9018 Grand Forks, ND 58202-9018 


\section{DOE DISCLAIMERS}

This report was prepared as an account of work sponsored by an agency of the United States Government. Neither the United States Government, nor any agency thereof, nor any of their employees makes any warranty, express or implied, or assumes any legal liability or responsibility for the accuracy, completeness, or usefulness of any information, apparatus, product, or process disclosed or represents that its use would not infringe privately owned rights. Reference herein to any specific commercial product, process, or service by trade name, trademark, manufacturer, or otherwise does not necessarily constitute or imply its endorsement, recommendation, or favoring by the United States Government or any agency thereof. The views and opinions of authors expressed herein do not necessarily state or reflect those of the United States Government or any agency thereof.

This report is available to the public from the National Technical Information Service, U.S. Department of Commerce, 5285 Port Royal Road, Springfield, VA 22161; phone orders accepted at (703) $487-4650$.

This report was prepared with the support of the U.S. Department of Energy (DOE) National Energy Technology Laboratory Cooperative Agreement No. DE-FC26-98FT40321. However, any opinions, findings, conclusions, or recommendations expressed herein are those of the authors(s) and do not necessarily reflect the views of DOE.

\section{EERC DISCLAIMER}

LEGAL NOTICE. This research report was prepared by the Energy \& Environmental Research Center (EERC), an agency of the University of North Dakota, as an account of work sponsored by the Nickel Producers Environmental Research Association. Because of the research nature of the work performed, neither the EERC nor any of its employees makes any warranty, express or implied, or assumes any legal liability or responsibility for the accuracy, completeness, or usefulness of any information, apparatus, product, or process disclosed, or represents that its use would not infringe privately owned rights. Reference herein to any specific commercial product, process, or service by trade name, trademark, manufacturer, or otherwise does not necessarily constitute or imply its endorsement or recommendation by the EERC.

\section{ACKNOWLEDGMENT}

This investigation was supported by the Nickel Producers Environmental Research Association through the Energy \& Environmental Research Association's (EERC) Jointly Sponsored Research Program, which is supported by the U.S. Department of Energy's (DOE) National Energy Technology Laboratory under Cooperative Agreement No. DE-FC26-98FT40321. We are grateful to Mr. Kenneth P. Larson of the Broward County Commission, Department of Planning and Environmental Protection, Air Quality Division for facilitating the EERC sampling of urban particulate matter at their State and Local Air Monitoring Stations/ National Air Monitoring System site in Davie, Florida. The x-ray absorption fine structure (XAFS) spectroscopy experiments were conducted at the Stanford Synchrotron Radiation Laboratory, Stanford University, California, and the National Synchrotron Light Source, Brookhaven National Laboratory, New York, both of which are supported by DOE. XAFS analyses were also supported in part from a U.S. National Science Foundation Collaborative Research Activities in Environmental Molecular Science grant (CHE0089133) to the University of Kentucky. 


\section{NICKEL SPECIATION OF AMBIENT PARTICULATE MATTER IN URBAN AIR}

\begin{tabular}{|c|c|c|}
\hline \multicolumn{3}{|c|}{ ABSTRACT } \\
\hline \multicolumn{3}{|c|}{$\begin{array}{l}\text { A four-step sequential Ni extraction method, summarized in Table AB-1, was evaluated for } \\
\text { identifying and quantifying the Ni species occurring in urban total suspended particulate (TSP) } \\
\text { matter and fine particulate matter }\left(<10 \mu \mathrm{m}\left[\mathrm{PM}_{10}\right] \text { and }<2.5 \mu \mathrm{m}\left[\mathrm{PM}_{2.5}\right] \text { in aerodynamic diameter). }\right. \\
\text { The extraction method was originally developed for quantifying soluble, sulfidic, elemental, and } \\
\text { oxidic forms of Ni that may occur in industrial atmospheres. X-ray diffraction (XRD) and X-ray } \\
\text { absorption fine structure (XAFS) spectroscopy were used to evaluate the Ni species selectivity of } \\
\text { the extraction method. Uncertainties in the chemical speciation of Ni in urban } \mathrm{PM}_{10} \text { and } \mathrm{PM}_{2.5} \\
\text { greatly affect inhalation health risk estimates, primarily because of the large variability in acute, } \\
\text { chronic, and cancer-causing effects for different Ni compounds. }\end{array}$} \\
\hline Step & Description & Ni Form \\
\hline I & $\begin{array}{l}15-\mathrm{mL} \text { deionized } \mathrm{H}_{2} \mathrm{O} \text {, mix for } 10 \mathrm{~s} \text {, expose for } 30 \mathrm{~min} \text {, centrifuge } \\
10 \mathrm{~min} \text { at } 3000 \mathrm{rpm}\end{array}$ & Soluble \\
\hline II & $\begin{array}{l}\text { 15-mL } 1: 130 \% \mathrm{H}_{2} \mathrm{O}_{2}-0.1 \mathrm{M} \text { citrate, mix for } 10 \mathrm{~s} \text {, expose for } 30 \mathrm{~min} \text {, } \\
\text { centrifuge } 10 \mathrm{~min} \text { at } 3000 \mathrm{rpm}\end{array}$ & Sulfidic \\
\hline III & $\begin{array}{l}\text { 10-mL 50:1 methanol-bromine solution, mix for } 10 \mathrm{~s} \text {, expose for } \\
20 \mathrm{~min} \text {, centrifuge } 10 \mathrm{~min} \text { at } 3000 \mathrm{rpm}\end{array}$ & Metallic \\
\hline IV & $\begin{array}{l}0.5-\mathrm{mL} \mathrm{HF}-1 \mathrm{~mL} \mathrm{HNO}_{3}-0.5 \mathrm{~mL} \mathrm{HCl} \text {, microwave } 4 \text { min at } 600 \mathrm{~W} \text {; wait } \\
1 \mathrm{~min} \text {, then } 4 \mathrm{~min} \text { at } 600 \mathrm{~W}\end{array}$ & Oxidic \\
\hline
\end{tabular}

A mixture of nickel sulfate hexahydrate $\left(\mathrm{NiSO}_{4} \cdot 6 \mathrm{H}_{2} \mathrm{O}\right)$, nickel subsulfide $\left(\mathrm{Ni}_{3} \mathrm{~S}_{2}\right)$, metallic nickel $\left(\mathrm{Ni}^{0}\right)$, and nickel oxide $(\mathrm{NiO})$ was analyzed eight times using the sequential $\mathrm{Ni}$ extraction method. Chemical mass balance considerations and XRD and XAFS spectroscopy analyses of extraction residues indicated that the soluble $\mathrm{Ni}$ extraction procedure provided a reliable estimate of $\mathrm{NiSO}_{4} \cdot 6 \mathrm{H}_{2} \mathrm{O}$ concentration but underestimated $\mathrm{Ni}_{3} \mathrm{~S}_{2}$ and $\mathrm{NiO}$ and overestimated $\mathrm{Ni}^{0}$ concentrations.

A National Institute of Standards and Technology urban TSP standard reference material (SRM) 1648 (urban TSP from St. Louis, Missouri) was analyzed in quadruplicate using the sequential $\mathrm{Ni}$ extraction method. Extraction results indicated that soluble and oxidic $\mathrm{Ni}$ forms accounted for about $80 \%$ of the total Ni in SRM 1648 and sulfidic and metallic Ni forms accounted for $20 \%$ of the remaining Ni. XAFS spectroscopy analyses of SRM 1648 extraction residues, however, were inconclusive for corroborating $\mathrm{Ni}$ species results because of an uneven and insufficient filter particle loading. 
TSP, $\mathrm{PM}_{10}$, and $\mathrm{PM}_{2.5}$ were sampled continuously using a high-volume air sampler, an automatic cartridge collection unit, and sequential air sampler, respectively, during August 26-31, 2002, from an urban air monitoring site in Davie, Florida. Total mass loadings on the filters corresponded to average concentrations of airborne TSP, $\mathrm{PM}_{10}$, and $\mathrm{PM}_{2.5}$ of 26.8, 10.4, and $6.3 \mu \mathrm{g} / \mathrm{m}^{3}$, respectively. An insufficient amount of $\mathrm{PM}_{2.5}$ was sampled to quantify $\mathrm{Ni}$ and perform speciation measurements. TSP and $\mathrm{PM}_{10} \mathrm{Ni}$ concentrations ( $86 \mathrm{ppm}$ and $\approx 140 \mathrm{ppm}$ ) correspond to airborne Ni concentrations of 2.3 and $1.5 \mathrm{ng} / \mathrm{m}^{3}$, respectively. These low Ni concentrations probably represent the atmospheric burden of "background" Ni derived from long-range transport via the North Atlantic trade winds.

Sequential Ni extraction and XAFS results indicated that $\mathrm{NiSO}_{4} \cdot \mathrm{xH}_{2} \mathrm{O}$ and a nickel oxide compound, possibly $\mathrm{NiFe}_{2} \mathrm{O}_{4}$, were the dominant Ni species occurring in Davie, Florida, TSP. Both methods also indicated that a small proportion of NiS was present. XAFS spectroscopy analyses indicated that the sequential $\mathrm{Ni}$ extraction procedure selectively and quantitatively removed $\mathrm{NiSO}_{4}$. $\mathrm{xH}_{2} \mathrm{O}$ from Davie TSP but overestimated the sulfidic $\mathrm{Ni}$ and $\mathrm{Ni}^{0}$ fractions and underestimated oxidic Ni. Davie $\mathrm{PM}_{10}$ lacked NiS, but $\mathrm{NiSO}_{4} \cdot \mathrm{xH}_{2} \mathrm{O}$ was more abundant than in TSP, probably because of the greater surface area of $\mathrm{PM}_{10}$ on which $\mathrm{NiSO}_{4} \cdot \mathrm{xH}_{2} \mathrm{O}$ heterogeneously condensed or adsorbed.

Automated scanning electron microscopy analyses of 800-1100 particles/sample indicated that $8 \%-15 \%$ of the total number of particles sampled from Davie, Florida, contained significant $\mathrm{Ni}$ concentrations, $\geq 10 \mathrm{wt} \%$. Most of these Ni-bearing particles were $<10 \mu \mathrm{m}$ in diameter suggesting that they primarily originated from combustion sources.

Direct metal speciation techniques such as XAFS spectroscopy should be used to verify the applicability and reliability of sequential $\mathrm{Ni}$ extraction methods before they are employed on a specific sample type (raw materials, workplace dust, ambient air TSP, $\mathrm{PM}_{10}, \mathrm{PM}_{2.5}$, etc.). The limitations of sequential $\mathrm{Ni}$ extraction methods applied to urban TSP, $\mathrm{PM}_{10}$, and $\mathrm{PM}_{2.5}$ samples need to be considered when using such indirect $\mathrm{Ni}$ speciation results to assess the potential inhalation health risks associated with individual Ni species. 


\section{TABLE OF CONTENTS}

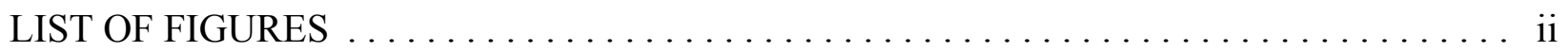

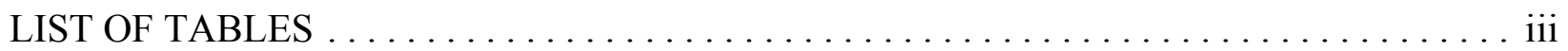

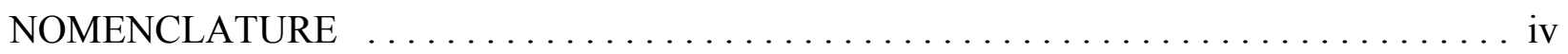

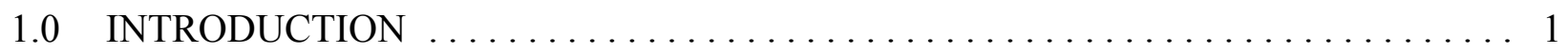

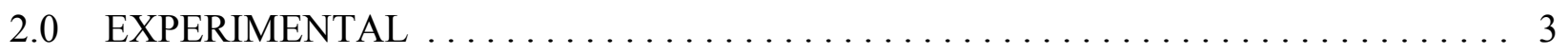

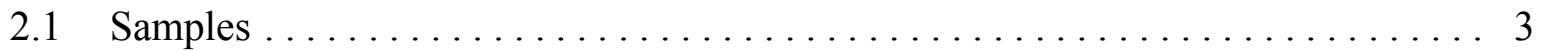

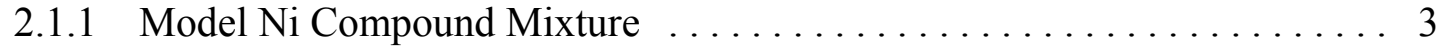

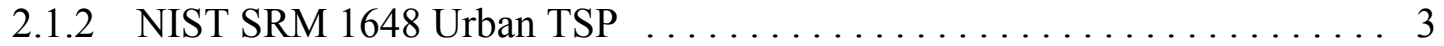

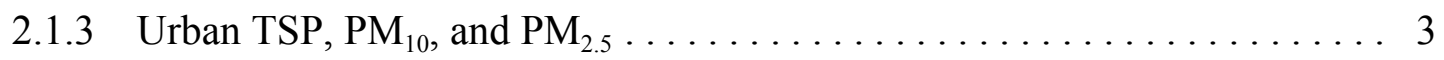

$2.2 \quad$ Sequential Ni Extractions and Analyses $\ldots \ldots \ldots \ldots \ldots \ldots \ldots \ldots \ldots \ldots \ldots$

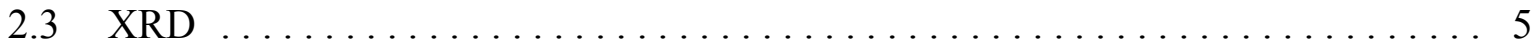

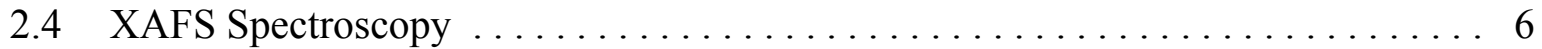

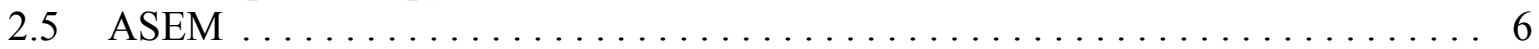

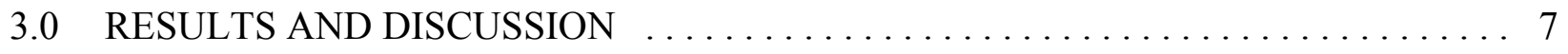

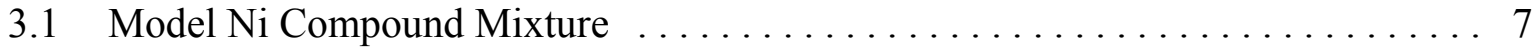

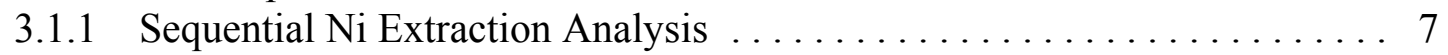

3.1.2 XRD and XAFS Spectroscopy Analyses $\ldots \ldots \ldots \ldots \ldots \ldots \ldots \ldots$

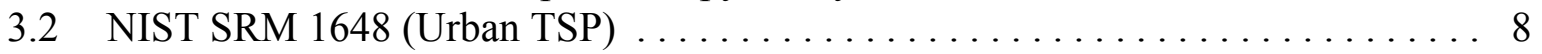

3.2.1 Sequential Ni Extraction Analysis $\ldots \ldots \ldots \ldots \ldots \ldots \ldots \ldots \ldots \ldots$

3.2.2 XAFS Spectroscopy Analysis .......................... 13

3.3 Urban (Davie, Florida) TSP, $\mathrm{PM}_{10}$, and $\mathrm{PM}_{2.5} \ldots \ldots \ldots \ldots \ldots \ldots \ldots \ldots \ldots \ldots$

3.3.1 Mass Loadings and $\mathrm{Ni}$ Concentrations ...................... 13

3.3 .2 XRD Analysis .................................... 14

3.3.3 Sequential Ni Extraction Analysis ....................... 14

3.3.4 Sulfur K-Edge XAFS Spectroscopy Analyses . . . . . . . . . . . . 15

3.3.5 Nickel K-Edge XAFS Spectroscopy Analyses . . . . . . . . . . . . . . . 17

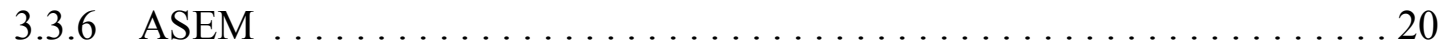

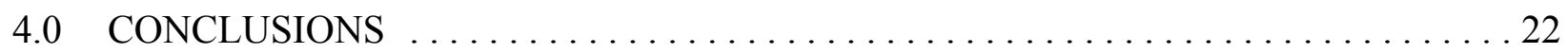

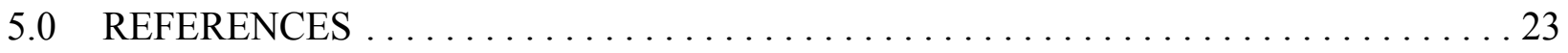

SEQUENTIAL NICKEL EXTRACTION RESULTS $\ldots \ldots \ldots \ldots \ldots \ldots \ldots$ Appendix A 


\section{LIST OF FIGURES}

1 Davie, Florida, SLAMS/NAMS site, major $\mathrm{PM}_{10}$ point source, Fort Lauderdale International Airport, and Port Everglade locations and a wind rose diagram for the

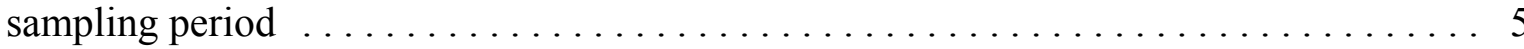

2 Mean Ni extraction recoveries for model $\mathrm{Ni}$ compound mixture $\ldots \ldots \ldots \ldots \ldots 7$

$3 \mathrm{XRD}$ pattern of soluble $\mathrm{Ni}$ extraction residue prepared from a standard $\mathrm{NiSO}_{4}$.

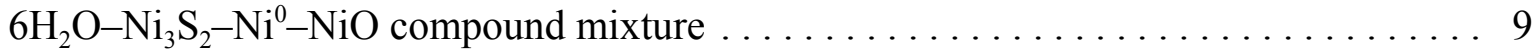

4 XRD pattern of sulfidic $\mathrm{Ni}$ extraction residue prepared from a standard $\mathrm{NiSO}_{4}$. $6 \mathrm{H}_{2} \mathrm{O}-\mathrm{Ni}_{3} \mathrm{~S}_{2}-\mathrm{Ni}^{0}-\mathrm{NiO}$ compound mixture $\ldots \ldots \ldots \ldots \ldots \ldots \ldots \ldots \ldots \ldots \ldots$

5 XRD pattern of $\mathrm{Ni}^{0}$ extraction residue prepared from a standard $\mathrm{NiSO}_{4}$.

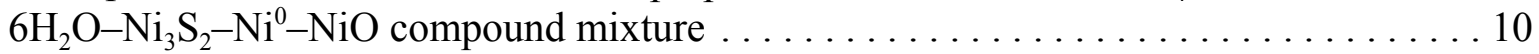

6 Ni K-edge XANES spectra of three Ni extraction residues prepared from a standard

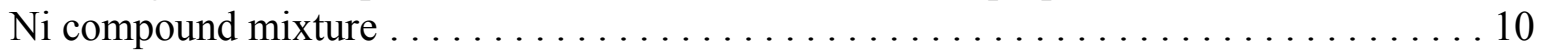

7 Comparison of calculated and measured (XANES) soluble Ni extraction residue

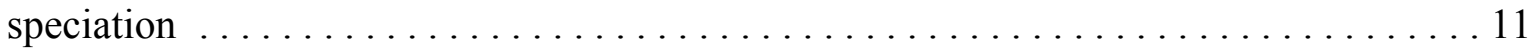

8 Comparison of calculated and measured (XANES) sulfidic Ni extraction residue

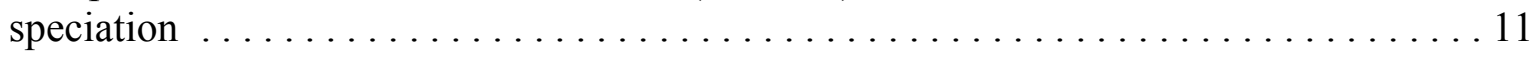

9 Comparison of calculated and measured (XANES) $\mathrm{Ni}^{0}$ extraction residue speciation $\ldots 12$

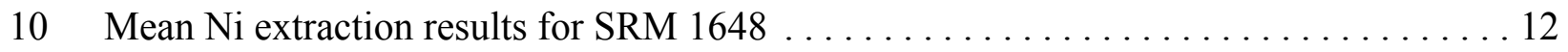

11 XRD pattern of HVAS filter containing TSP from Davie, Florida $\ldots \ldots \ldots \ldots \ldots \ldots$

12 Average of duplicate Ni extraction results for urban TSP collected in Davie, Florida . . 15

13 Sulfur K-edge XAFS spectra of ACCU $\left(\mathrm{PM}_{10}\right)$ and SAS $\left(\mathrm{PM}_{2.5}\right)$ filter blanks and filters

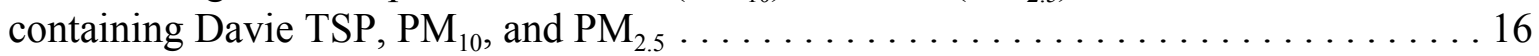

14 Sulfur XANES spectra of SAS filter blank and filters containing Davie TSP, $\mathrm{PM}_{10}$, and

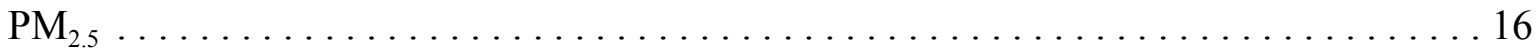

15 Ni K-edge XAFS spectra of HVAS, ACCU, and SAS filter blanks and filters containing

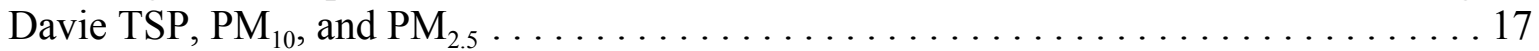

Continued... 


\section{LIST OF FIGURES (continued)}

16 Ni K-edge XANES spectra of the filters containing Davie TSP and $\mathrm{PM}_{10} \ldots \ldots \ldots$

17 Comparison of sequential Ni extraction and XANES analysis results for Davie TSP . . 19

18 Ni K-edge XAFS spectra of a HVAS filter blank, HVAS filter blank from the soluble Ni (Step I) extraction, and a HVAS filter containing Davie TSP residue from the soluble Ni

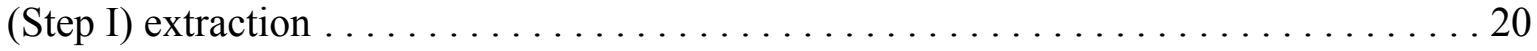

19 Number concentrations of Ni-bearing ( $\geq 10 \mathrm{wt} \%)$ particles in Davie TSP samples . . . . 21

20 Particle-size distribution of Ni-bearing $(\geq 10 \mathrm{wt} \%)$ particles in Davie TSP . . . . . . 21

\section{LIST OF TABLES}

1 Four-Step Ni Extraction Procedure Developed by Luk et al. $\ldots \ldots \ldots \ldots \ldots \ldots$

2 High-Volume Aerosol Sampling Parameters $\ldots \ldots \ldots \ldots \ldots \ldots \ldots \ldots \ldots$

3 Comparison of SRM 1648 and Davie TSP Ni Concentrations . . . . . . . . . . . 14

4 XANES Ni Speciation Results for Davie $\mathrm{TSP}$ and $\mathrm{PM}_{10} \ldots \ldots \ldots \ldots \ldots \ldots$

$5 \quad \mathrm{Ni}$ Species Concentrations for Davie $\mathrm{TSP}$ and $\mathrm{PM}_{10} \ldots \ldots \ldots \ldots \ldots$ 


\section{NOMENCLATURE}

ACCU automatic cartridge collection unit

ASEM automated scanning electron microscopy

CAAA Clean Air Act Amendments

EPA U.S. Environmental Protection Agency

EPMA electron probe microanalysis

GFAAS graphite furnace atomic absorption spectroscopy

HVAS high-volume air sampler

ICP-AES inductively coupled plasma-atomic emission spectroscopy

$\mathrm{m}^{3} \quad$ cubic meter

NAMS National Air Monitoring System

ng nanogram $\left(10^{-9} \mathrm{~g}\right)$

$\mathrm{Ni}^{0} \quad$ metallic nickel

$\mathrm{Ni}_{3} \mathrm{~S}_{2} \quad$ nickel subsulfide

NSLS National Synchrotron Light Source

NIST National Institute of Standards and Technology

PM particulate matter

$\mathrm{PM}_{10} \quad$ particulate matter with aerodynamic diameters $<10 \mu \mathrm{m}$

$\mathrm{PM}_{2.5} \quad$ particulate matter with aerodynamic diameters $<2.5 \mu \mathrm{m}$

ppm part per million

s second

SAS sequential air sampler

SLAMS State and Local Air Monitoring Station

SRM standard reference material

SSRL Stanford Synchrotron Radiation Laboratory

TRI Toxics Release Inventory

TSP total suspended particulate

$\mu \mathrm{g} \quad$ microgram $\left(10^{-6} \mathrm{~g}\right)$

wt $\% \quad$ weight percent

XAFS $\quad \mathrm{X}$-ray absorption fine structure

XANES $\mathrm{x}$-ray absorption near edge structure

XRD $\quad \mathrm{X}$-ray diffraction 


\section{NICKEL SPECIATION OF AMBIENT PARTICULATE MATTER IN URBAN AIR}

\subsection{INTRODUCTION}

Nickel (Ni) is a transition metal that occurs throughout the environment as it is discharged into air, water, and soil from various natural and industrial sources. A significant natural source of atmospheric $\mathrm{Ni}$ is windborne dust particles derived from the weathering of rocks and soils and from volcanic eruptions. ${ }^{1}$ The average Ni concentration of crustal rocks is $75 \mathrm{ppm}^{2}$ Although Ni is a ubiquitous metal, industrialization has increased its flux into the environment. ${ }^{3}$ Anthropogenic stationary sources that release Ni into ambient air include 1) combustion and incineration sources (oil- and coal-burning units in utility, industrial, and residential sectors and medical, municipal, and sewage sludge incinerators); 2) high-temperature metallurgical operations (steel and Ni alloy manufacturing, secondary metals smelting, and coproduct Ni recovery); 3) primary production operations (mining, milling, smelting, and refining); and 4) chemical and catalyst sources (Ni chemical manufacturing, electroplating, $\mathrm{Ni}-\mathrm{Cd}$ battery manufacturing, and catalyst production, use, and reclamation). ${ }^{4,5}$ The mobile source contribution to Ni emission inventories is small and derives primarily from engine wear and impurities in engine oil and fuel additives. ${ }^{6}$ However, commercial marine vessels are significant mobile sources of $\mathrm{Ni}$ in areas near harbors. ${ }^{7}$

Ni-bearing particles occur in the atmosphere as part of suspended particulate matter (PM) and, rarely, of mist aerosols. Ni is most commonly associated with the fine PM fraction of ambient air samples with diameters ranging from 0.6 to $10 \mu \mathrm{m} .{ }^{8}$ These fine Ni-bearing particles are susceptible to human inhalation and, therefore, pose significant health concerns. Particles with aerodynamic diameters less than $10 \mu \mathrm{m}\left(\mathrm{PM}_{10}\right)$ are likely to penetrate beyond the nose, and those less than $2.5 \mu \mathrm{m}$ $\left(\mathrm{PM}_{2.5}\right)$ are likely to penetrate deep into the lung.

The Ni concentration of PM in the U.S. atmosphere ranges from 0.01 to $60,0.6$ to 78 , and 1 to $328 \mathrm{ng} / \mathrm{m}^{3}$ in remote, rural, and urban areas, respectively. ${ }^{9}$ Sunderman and Oskarsson ${ }^{10}$ reported that $\mathrm{Ni}$ concentrations in ambient air average $6 \mathrm{ng} / \mathrm{m}^{3}$ in rural areas, $25 \mathrm{ng} / \mathrm{m}^{3}$ in urban areas, and $170 \mathrm{ng} / \mathrm{m}^{3}$ in large metropolitan or industrial areas. Average ambient air Ni concentrations in U.S. and Canadian cities range from 5 to $50 \mathrm{ng} / \mathrm{m}^{3}$ and 1 to $20 \mathrm{ng} / \mathrm{m}^{3}$, respectively. ${ }^{11,12}$

In the United States, the impetus for focusing on individual elements, such as $\mathrm{Ni}$, in air pollution derives from the 1990 Clean Air Act Amendments (CAAA) ${ }^{13}$ and, more recently, the attainment of National Ambient Air Quality Standards. ${ }^{14}$ Similar legislation has been enacted or proposed in many other countries as well. Title III of the CAAA identifies 189 chemicals, including $\mathrm{Ni}$ and 15 other inorganic trace elements (As, Be, Cd, Cl, Co, Cr, F, Hg, Mn, P, Pb, Sb, Se, Th, and $\mathrm{U})$, as potential hazardous air pollutants or air toxics. Many stationary sources have had to report $\mathrm{Ni}$ emissions as part of the U.S. Environmental Protection Agency's (EPA) Toxics Release Inventory (TRI). ${ }^{15}$ Although TRI and similar reporting provide estimates of the amounts of $\mathrm{Ni}$ released into the environment, they are not an indicator of toxicity because the acute, chronic, and cancer-causing effects vary significantly for the different chemical species of Ni. For example, nickel subsulfide $\left(\mathrm{Ni}_{3} \mathrm{~S}_{2}\right)$ is considered the most carcinogenic $\mathrm{Ni}$ species on the basis of available human epidemiology and animal studies. ${ }^{5,11,12,16}$ The carcinogenicity of water-soluble Ni salts such as $\mathrm{NiSO}_{4} \cdot \mathrm{xH}_{2} \mathrm{O}$ and 
insoluble nickel oxide compounds such as Ni-containing spinels (e.g., $\mathrm{NiFe}_{2} \mathrm{O}_{4}$ ), however, is controversial. ${ }^{5,16,17}$ Therefore, understanding the speciation of $\mathrm{Ni}$ in ambient air is of the utmost importance for assessing potential respiratory health risks associated with $\mathrm{Ni}$.

The primary purpose of this investigation was to evaluate an improved sequential $\mathrm{Ni}$ extraction method, summarized in Table 1, for its application to Ni ambient air samples. This method, developed by Luk et al. ${ }^{18}$ for the Nickel Producers Environmental Research Association, improved the Zatka et al. ${ }^{19}$ sequential Ni extraction method by incorporating the following modifications: 1) replaced filtration with centrifugation, 2) replaced conventional hot plate sample dissolution approach with microwave digestion, 3) optimized extraction durations, and 4) modified the leaching reagents. Bolt et al. ${ }^{20}$ and Füchtjohann et al. ${ }^{21}$ have also recently proposed improved sequential Ni extraction methods. These methods are based on treating a small but representative sample of PM with successive leaching steps to separate analyte Ni species from the sample matrix. $\mathrm{Ni}$ species concentrations in the extracted fractions are then determined using sensitive analytical techniques, such as graphite furnace atomic absorption spectroscopy (GFAAS) and inductively coupled plasma-atomic emission spectroscopy (ICP-AES). Sequential extractions provide an operationally defined (i.e., based on solubility differences) determination of $\mathrm{Ni}$ species (soluble, sulfidic, metallic, and oxidic). These methods are also useful for evaluating the environmental mobility and bioavailability of $\mathrm{Ni}$.

Table 1. Four-Step Ni Extraction Procedure Developed by Luk et al. ${ }^{18}$

\begin{tabular}{|c|c|c|}
\hline Step & Description & Ni Form \\
\hline I & $\begin{array}{l}15-\mathrm{mL} \text { deionized } \mathrm{H}_{2} \mathrm{O} \text {, mix for } 10 \mathrm{~s} \text {, expose for } 30 \mathrm{~min} \text {, centrifuge } \\
10 \mathrm{~min} \text { at } 3000 \mathrm{rpm}\end{array}$ & Soluble \\
\hline II & $\begin{array}{l}15-\mathrm{mL} 1: 130 \% \mathrm{H}_{2} \mathrm{O}_{2}-0.1 \mathrm{M} \text { citrate, mix for } 10 \mathrm{~s} \text {, expose for } 30 \mathrm{~min} \text {, } \\
\text { centrifuge } 10 \mathrm{~min} \text { at } 3000 \mathrm{rpm}\end{array}$ & Sulfidic \\
\hline III & $\begin{array}{l}\text { 10-mL 50:1 methanol-bromine solution, mix for } 10 \mathrm{~s} \text {, expose for } \\
20 \mathrm{~min} \text {, centrifuge } 10 \mathrm{~min} \text { at } 3000 \mathrm{rpm}\end{array}$ & Metallic \\
\hline IV & $\begin{array}{l}0.5-\mathrm{mL} \mathrm{HF}-1 \mathrm{~mL} \mathrm{HNO}_{3}-0.5 \mathrm{~mL} \mathrm{HCl} \text {, microwave } 4 \mathrm{~min} \text { at } 600 \mathrm{~W} \text {; wait } \\
1 \mathrm{~min} \text {, then } 4 \mathrm{~min} \text { at } 600 \mathrm{~W}\end{array}$ & Oxidic \\
\hline
\end{tabular}

Ni speciation analyses were conducted on a known Ni compound mixture, a National Institute for Standards and Technology (NIST) standard reference material (SRM 1648), and an urban total suspended particulate (TSP) sample collected from Davie, Florida, using Luk et al.'s ${ }^{18}$ improved sequential Ni extraction method. Two complementary methods: $\mathrm{x}$-ray diffraction (XRD) and/or Xray absorption fine structure (XAFS) spectroscopy were also used for determining the Ni speciation of TSP, $\mathrm{PM}_{10}$, and $\mathrm{PM}_{2.5}$ samples and Ni extraction residues from TSP samples. The XAFS technique is especially well suited for determining $\mathrm{Ni}$ speciation because it can directly and nondestructively analyze TSP, $\mathrm{PM}_{10}$, and $\mathrm{PM}_{2.5}$ filter samples with ppm sensitivity. ${ }^{22-25}$ XAFS spectroscopy, a definitive speciation technique, involves recording the variation of the $\mathrm{x}$-ray absorption coefficient, as a function of energy, in the vicinity of a characteristic absorption edge for the element of interest. The $\mathrm{x}$-ray flux is supplied from a very intense synchrotron $\mathrm{x}$-ray source. Analysis of variations in the 
$\mathrm{x}$-ray absorption coefficient provides structural information concerning the local environment of the analyte element, in terms of oxidation state, interatomic distances, and the type and number of coordinating ligands. The primary limitations of this direct speciation analysis technique are that the structural information obtained represents a weighted average for all the different chemical species of an element that may exist in a sample and the requirement of a synchrotron x-ray source. The capability of XAFS spectroscopy to directly determine Ni speciation was used to evaluate the Ni species selectivity of sequential extractions and to corroborate speciation results. Automated scanning electron microscopy (ASEM) was also used to determine the number concentrations (frequency \%) of Ni-containing particles in TSP samples and to evaluate the particle-size distributions of $\mathrm{Ni}$.

\subsection{EXPERIMENTAL}

\subsection{Samples}

\subsubsection{Model Ni Compound Mixture}

Four reagent-grade $\mathrm{Ni}$ compounds, 1) nickel sulfate hexahydrate $\left.\left(\mathrm{NiSO}_{4} \cdot 6 \mathrm{H}_{2} \mathrm{O}\right), 2\right) \mathrm{Ni}_{3} \mathrm{~S}_{2}$, 3) metallic nickel $\left(\mathrm{Ni}^{0}\right)$, and 4) green nickel oxide $(\mathrm{NiO})$, were used to prepare a mixture of known $\mathrm{Ni}$ compounds. An XRD analysis of the $\mathrm{Ni}_{3} \mathrm{~S}_{2}$ compound indicated that it is contaminated with a very small amount of an additional sulfidic $\mathrm{Ni}$ compound, $\mathrm{Ni}_{7} \mathrm{~S}_{6}$. Approximately $200 \mathrm{mg}$ of each compound was weighed in a $20-\mathrm{mL}$ capacity plastic scintillation vial. Several glass mixing beads were added, and the vial was shaken in an SPEX mixer mill for $15 \mathrm{~min}$ to homogenize the mixture. The model nickel compound mixture consisted of $25 \mathrm{wt} \% \mathrm{NiSO}_{4} \cdot 6 \mathrm{H}_{2} \mathrm{O}, 26 \mathrm{wt} \% \mathrm{Ni}_{3} \mathrm{~S}_{2}, 23 \mathrm{wt} \% \mathrm{Ni}^{0}$, and $26 \mathrm{wt} \% \mathrm{NiO}$.

\subsubsection{NIST SRM 1648 Urban TSP}

SRM 1648 consists of atmospheric TSP collected in an urban location of St. Louis, Missouri. NIST collected TSP in a specially designed baghouse for a period in excess of 12 months and, therefore, it is a time-integrated sample. SRM 1648 was used in this investigation, as intended by NIST, to typify the analytical problems of TSP samples obtained from industrialized urban areas. SRM 1648 is sold in 2-g portions, and Ni is a sufficiently concentrated, certified concentration of $82 \pm 3 \mathrm{ppm}$, in it for sequential Ni extraction and XAFS speciation analyses.

\subsubsection{Urban TSP, $\mathrm{PM}_{10}$, and PM 2.5}

Ambient TSP, $\mathrm{PM}_{10}$, and $\mathrm{PM}_{2.5}$ were sampled continuously during August 26-31, 2002, from an urban State and Local Air Monitoring Stations (SLAMS) and National Air Monitoring System (NAMS) site located in Davie, Florida $\left(26.08^{\circ} \mathrm{N}, 80.24^{\circ} \mathrm{W}\right)$. The Broward County Air Quality Division utilizes this urban (citywide scale, 4-50 km) site to determine representative $\mathrm{PM}_{10}$ and $\mathrm{PM}_{2.5}$ concentrations in an area of high population density. According to the Broward County Planning Services Division, ${ }^{26}$ the 2002 population density of Broward County was 3837 persons $/ \mathrm{mi}^{2}$. 
The following equipment and EPA Compendium Methods ${ }^{27}$ were used to sample ambient TSP, $\mathrm{PM}_{10}$, and $\mathrm{PM}_{2.5}$ :

- Tapered electronic oscillating microbalance, Rupprecht \& Patashnick Model 1400a (EPA Compendium Method IO-1.3).

- Automatic cartridge collection unit (ACCU), Ruppecht \& Patashnick

- Sequential air sampler (SAS), Rupprecht \& Patashnick Model 2025 (EPA Compendium Method IO-2.3)

- High-volume air sampler (HVAS) and General Metal Works (EPA Compendium Method IO-2.1)

TSP was collected on Gelman Scientific Type A/E glass-fiber filters, whereas $\mathrm{PM}_{10}$ and $\mathrm{PM}_{2.5}$ were collected on Whatman GF/C glass fiber filters. Urban TSP was also collected on a moving carbon tape using a Burkard Seven-Day Recording Volumetric Spore Trap. Field filter blank samples were collected for quality control purposes. Meteorological conditions (e.g., temperature, wind speed and direction, and relative humidity) were also recorded during the sampling period. However, late in the sampling campaign, lightning struck the weather mast at the Davie site, and the recorded meteorological data were lost.

The locations of major $\mathrm{PM}_{10}$ point sources in relation to the sampling site and a wind rose diagram, created from hourly average wind speed and direction measurements from the Fort Lauderdale International Airport, for the sampling period are shown in Figure 1. The $\mathrm{PM}_{10}$ emission estimates in Figure 1 are based on 2001 statistics from the Florida Department of Environmental Protection. Point sources in the vicinity of the Davie site include residual (No. 6 fuel) oil- and gasburning power plants, cement kiln operations, and municipal waste incineration facilities. Significant mobile sources of TSP, $\mathrm{PM}_{10}$, and $\mathrm{PM}_{2.5}$ near the Davie site include motor vehicle, aircraft, and marine vessel traffic. Marine vessels are also potential Ni emission sources because most burn distillate and residual-grade fuel oils which generally contain significant $\mathrm{Ni}$ contents. ${ }^{7,28}$ Approximately 5400 ships call at Port Everglades a year. ${ }^{29}$ The wind rose diagram in Figure 1 indicates that winds were predominantly marine in origin and that mobile and point sources east-southeast and southeast from the Davie site probably contributed to TSP, $\mathrm{PM}_{10}$, and $\mathrm{PM}_{2.5}$ during the sampling period. Two meteorological processes that occurred during the sampling period were synoptic southeast and easterly winds associated with the tropical North Atlantic trade winds and the formation of deep convective thunderstorm cells. Tall $(12-16 \mathrm{~km})$ convective thunderstorms were generally generated during the afternoon when moist air from the ocean breeze was carried aloft by the hot air masses rising off the southern peninsula of Florida. In contrast to low-altitude frontal storms, these tall convective thunderstorms scavenge PM from the middle and upper troposphere.

\subsection{Sequential Ni Extractions and Analyses}

The four-step extraction procedure summarized in Table 1 was evaluated for determining $\mathrm{Ni}$ speciation. The extraction procedure was designed specifically for determining the soluble, sulfidic, 

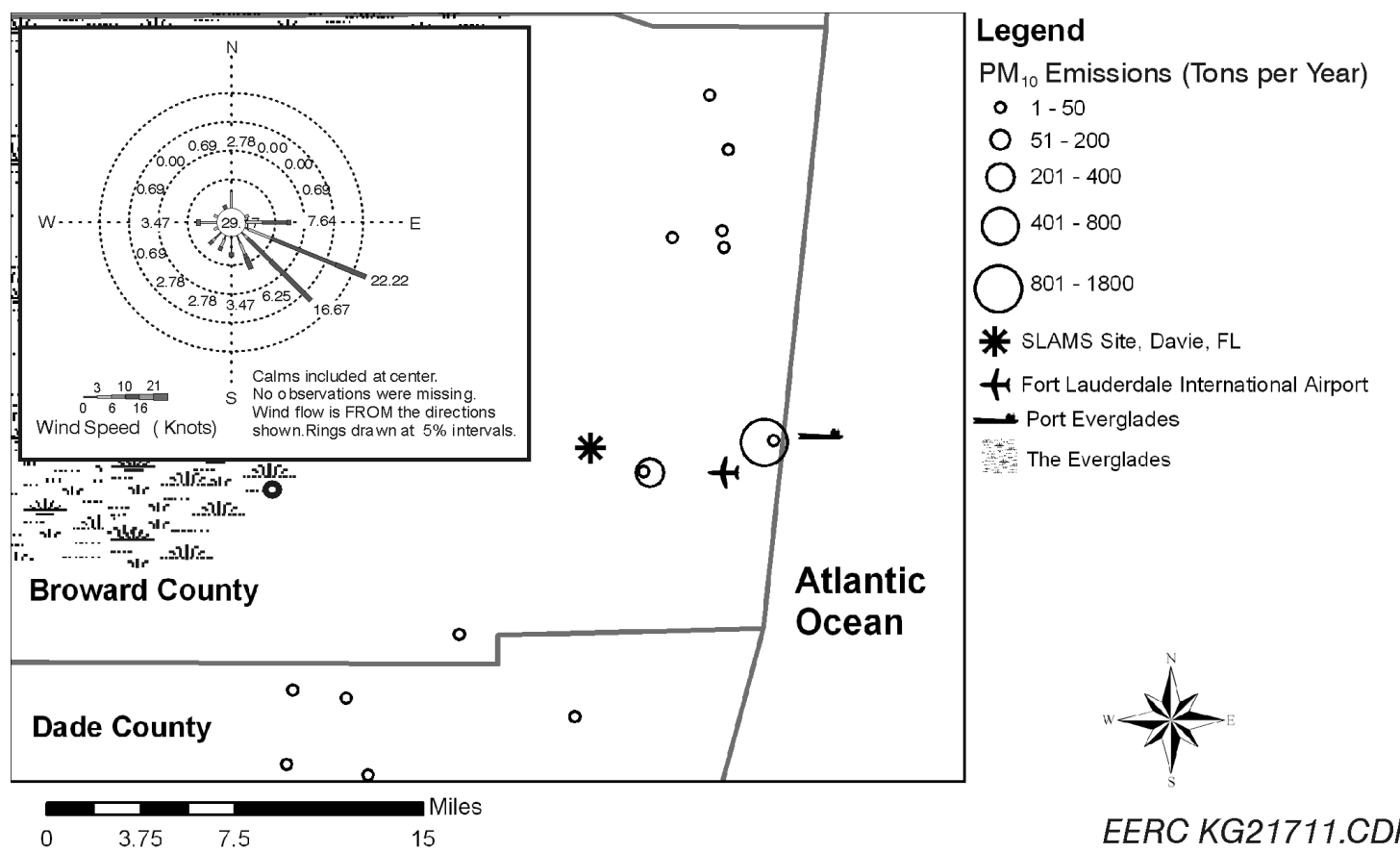

EERC KG21711.CDR

Figure 1. Davie, Florida, SLAMS/NAMS site, major PM $_{10}$ point source, Fort Lauderdale International Airport, and Port Everglade locations and a wind rose diagram for the sampling period.

metallic, and oxidic forms of $\mathrm{Ni}$ found in industrial atmospheres. $\mathrm{Ni}$ in each extract was quantified using GFAAS or ICP-AES. In addition, urban TSP, $\mathrm{PM}_{10}$, and $\mathrm{PM}_{2.5}$ samples and filter blanks were prepared using American Society for Testing and Materials Method D6357 $7^{30}$ and analyzed using GFAAS. The sulfur concentration of TSP was determined by performing the first two Ni extraction steps in Table 1 and analyzing the extracts by ion chromatography.

$\mathrm{Ni}$ extraction residues were prepared for XAFS spectroscopy analyses by performing the first three Ni extraction steps (Table 1). However, instead of separating the residue from the extraction fluid by centrifugation, they were separated by filtering on Whatman GF/C glass-fiber filters. Residues were then dried in an oven at $50^{\circ} \mathrm{C}$ before analyzing them using XAFS spectroscopy and XRD.

\subsection{XRD}

XRD analyses were performed on extraction residues and the Davie TSP sample to identify crystalline phases. XRD patterns were collected over $5^{\circ}-70^{\circ} 2 \theta$ with a Philips X'Pert theta-theta $\mathrm{x}$-ray diffractometer system operating at $40 \mathrm{kV}$ and $50 \mathrm{~mA}$ (graphite monochromatized $\mathrm{Cu} \mathrm{K-} \alpha$ radiation, $0.02^{\circ} 2 \theta$ steps, $3 \mathrm{sec} / \mathrm{step}$ ). Incident beam optics consisted of a programmable divergence slit fixed at $14^{\circ}$ and a $15-\mathrm{mm}$ wide-beam mask. Diffracted beam optics consisted of an antiscatter slit programmed for an automatic 10-mm irradiated length, programmable receiving slit set to a height of $0.35 \mathrm{~mm}$, soller slits, and a secondary monochromater. Diffraction peaks were identified using 
a Minerals Data Incorporated JADE+ processing software utilizing the ICDD PDF-2 inorganic and organic powder diffraction database, Sets $1-45$ on CD-ROM.

\subsection{XAFS Spectroscopy}

XAFS spectroscopy was performed at beam-line X-18B of the National Synchrotron Light Source (NSLS), Brookhaven National Laboratory, New York, during July 26-30, 2002, and at beam line 4-3 of the Stanford Synchrotron Radiation Laboratory (SSRL), Stanford University, California, during January 16-23 and February 18-24, 2003. The NSLS was operated at a constant voltage of $2.85 \mathrm{GeV}$, and the current generally decayed from 270 to $150 \mathrm{~mA}$ between fills every 12 hours. The synchrotron at SSRL was operated at a constant voltage of $3.00 \mathrm{GeV}$, and the current generally decayed from 100 to $65 \mathrm{~mA}$ between fills every 24 hours. Ni XAFS spectra were measured in absorption and fluorescence geometries. The latter spectra were obtained using a PIPS detector or a $12-\mathrm{GeV}$ array detector, depending on Ni concentration. Sulfur K-edge XAFS spectra were collected at the NSLS in fluorescence geometry using a PIBS detector, whereas at the SSRL a Lytle detector was used. A Co filter was also used to enhance the signal-to-noise ratio of the $\mathrm{Ni}$ fluorescent XAFS spectra. ${ }^{31}$ The Ni K-absorption edge at $8,333 \mathrm{eV}$ was defined as the major peak in the first derivative XAFS spectrum of a thin $\mathrm{Ni}^{0}$ foil acquired simultaneously in absorption geometry behind the main experiment. The $\mathrm{S} \mathrm{K}$-absorption edge at 2,472 eV was defined by the maximum white line absorption peak for an elemental sulfur calibration standard. Ni XAFS spectra were generated as a function of X-ray energy by rotating a double $\mathrm{Si}(220)$ crystal monochromator from about $100 \mathrm{eV}$ below the Ni K-edge to about $500 \mathrm{eV}$ above. For S, a Si(111) channel cut crystal monochromator was rotated from $72 \mathrm{eV}$ below and $250 \mathrm{eV}$ above the $\mathrm{S}$ K-edge. Multiple scans, typically between 3 and 5 scans, were combined to produce the overall spectrum.

Ni and S XAFS spectra were analyzed using the procedures described by Brown et al., ${ }^{32}$ Lee et al., ${ }^{33}$ and Koningsberger and Prins. ${ }^{34}$ First, the energy scale was calibrated with respect to the zero-point of energy defined by the calibration standard spectrum. Then the XAFS spectrum of the unknown sample was divided into separate x-ray absorption near-edge structure (XANES) and extended XAFS regions. The edge step parameter provided an approximation of Ni concentration. XANES spectra of reagent-grade Ni compounds and synthesized Ni compounds, acquired in previous investigations, ${ }^{25,35,36}$ were used essentially as "fingerprints" for identifying and quantifying $\mathrm{Ni}$ species. The following $\mathrm{Ni}$ compounds are included in this spectral database: $\mathrm{Ni}^{0}, \mathrm{NiS}, \mathrm{NiS}_{2}$, $\mathrm{Ni}_{3} \mathrm{~S}_{2}-\mathrm{Ni}_{7} \mathrm{~S}_{6}$ mixture, "green" $\mathrm{NiO}, \mathrm{Ni}(\mathrm{OH})_{2}, \mathrm{NiSO}_{4} \cdot \mathrm{xH}_{2} \mathrm{O}, \mathrm{C}_{4} \mathrm{H}_{6} \mathrm{NiO}_{4} \cdot 4 \mathrm{H}_{2} \mathrm{O}, \mathrm{NiCO}_{3}, \mathrm{NiFe}_{2} \mathrm{O}_{4}$, $\mathrm{MgNiO}_{2},\left(\mathrm{Mg}_{0.2}, \mathrm{Ni}_{0.8}\right)_{2} \mathrm{SiO}_{4}$, and $\left(\mathrm{Mg}_{0.85}, \mathrm{Ni}_{0.15}\right)_{2} \mathrm{SiO}_{4}$.

\subsection{ASEM}

The 20-mm-wide carbon tape from the Burkard Seven-Day Recording Volumetric Spore Trap was cut into 48-mm-long pieces representing a 24-hour period. Starting times were known, and the tapes were cut to represent 8:00 a.m.-5:00 p.m. sampling periods. These strips, representing 9 hours of TSP collection, were then mounted on a standard petrographic slide and inserted directly into the ASEM for analysis without further sample preparation. 
The ASEM method utilizes digital image analysis and electron probe microanalysis (EPMA) techniques to locate, size, and chemically analyze individual ash particles with submicron diameters as small as $0.3 \mu \mathrm{m}$. The analyses were conducted using a JEOL JSM-5800 SEM equipped with a Noran Instruments Voyager x-ray analysis and automation system. The SEM was operated at an accelerating voltage of $15 \mathrm{kV}$ and a beam current of $600 \mathrm{pA}$. EPMA of each particle was conducted for $10 \mathrm{~s}$. The following elements were analyzed: $\mathrm{Na}, \mathrm{Mg}, \mathrm{Al}, \mathrm{Si}, \mathrm{P}, \mathrm{S}, \mathrm{Cl}, \mathrm{K}, \mathrm{Ca}, \mathrm{Ti}, \mathrm{V}, \mathrm{Fe}$, and $\mathrm{Ni}$ using the atomic number, absorption, and fluorescence (ZAF) method which corrects $\mathrm{x}$-ray intensities for differences in the atomic number (Z), absorption (A), and fluorescent (F) effects of the calibration standards relative to the sample. The chemical compositions obtained in this manner are semiquantitative at best because of the short $\mathrm{x}$-ray counting time employed (10 s), the use of flat mineral standards for calibration, and the fact that no matrix corrections for particle diameter, shape, or density were applied.

\subsection{RESULTS AND DISCUSSION}

\subsection{Model Ni Compound Mixture}

\subsubsection{Sequential Ni Extraction Analysis}

Eight representative portions, $10-15 \mathrm{mg}$, of the known $\mathrm{Ni}$ compound mixture were analyzed to evaluate the selectivity of the four-step sequential $\mathrm{Ni}$ extraction method summarized in Table 1. The Ni extraction recoveries presented in Figure 2 (additional extraction data are also presented in

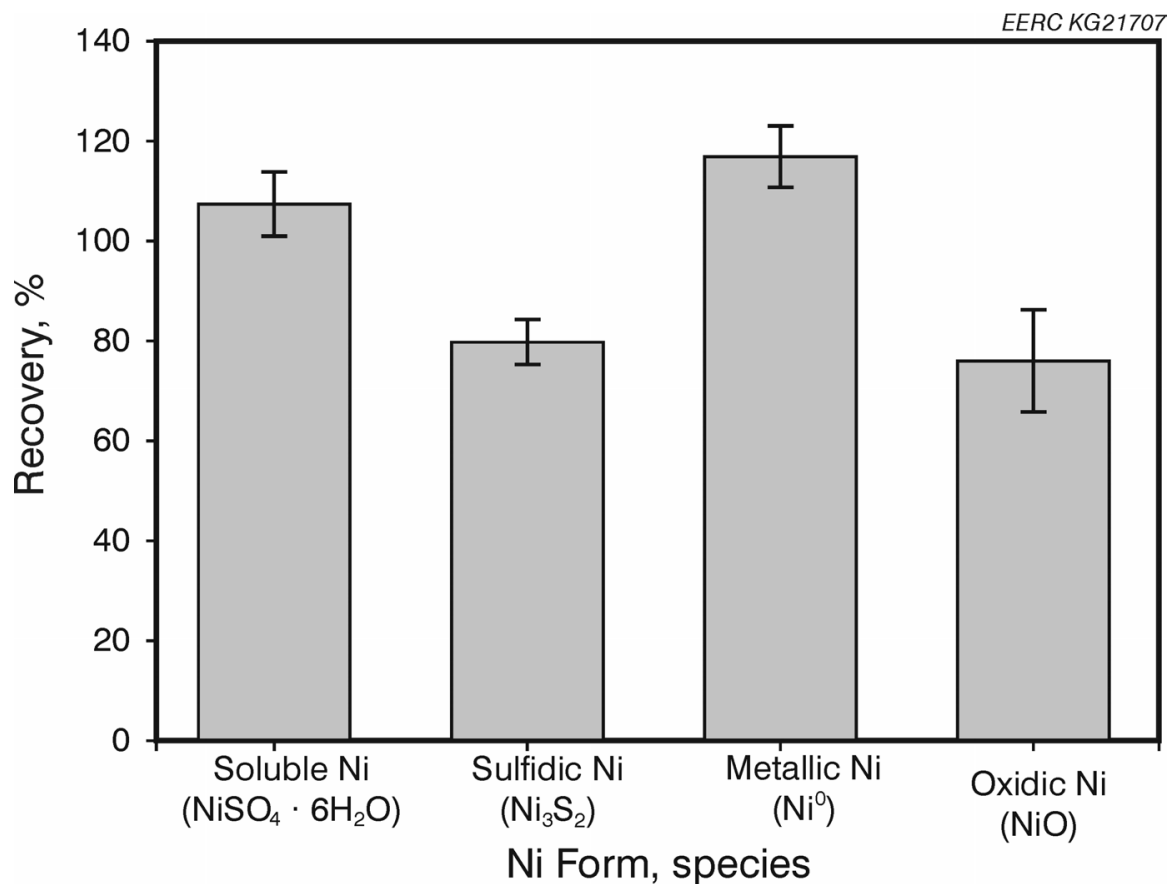

Figure 2. Mean Ni extraction recoveries for model Ni compound mixture. The error bars represent $\pm 95 \%$ confidence limits calculated from eight sequential Ni extraction measurements. 
Appendix A, Table A-1) indicate that the first extraction step recovered, on average, $107 \%$ of the soluble $\mathrm{NiSO}_{4} \cdot 6 \mathrm{H}_{2} \mathrm{O}$. Recoveries of the sulfidic $\left(\mathrm{Ni}_{3} \mathrm{~S}_{2}\right)$ and oxidic $(\mathrm{NiO})$ forms were biased low by about $20 \%$; conversely, $\mathrm{Ni}^{0}$ was biased high by about $20 \%$. Sulfidic $\mathrm{Ni}$ is probably biased low because of incomplete dissolution and/or sulfidic Ni separation resulting in $20 \mathrm{wt} \%$ less Ni extracted and $20 \mathrm{wt} \%$ more $\mathrm{Ni}$ remaining in the residue that is incorrectly measured as $\mathrm{Ni}^{0}$ during the subsequent extraction step. In addition, the partial dissolution of $\mathrm{Ni}_{3} \mathrm{~S}_{2}$ and its coextraction with soluble Ni during the first extraction step may have contributed to the low sulfidic Ni recovery. Oxidic $\mathrm{Ni}$ is presumably biased low because of incomplete sample digestion during the fourth extraction step. Results presented by Luk et al. ${ }^{18}$ for known Ni compound mixtures (Tables $11 \mathrm{a}-11 \mathrm{c}$ in Reference 18) also indicated greater soluble $\mathrm{Ni}$ and $\mathrm{Ni}^{0}$ recoveries relative to sulfidic and oxidic Ni recoveries.

\subsubsection{XRD and XAFS Spectroscopy Analyses}

The selectivity of the four-step sequential $\mathrm{Ni}$ extraction procedure was also investigated by repeating Step I, Step I and II, and Step I-III extractions on the model Ni compound mixture and then analyzing the residues using XRD and XAFS spectroscopy. XRD spectra of the three extraction residues in Figures 3-5 indicate that the first extraction step effectively removed soluble $\mathrm{NiSO}_{4}$. $6 \mathrm{H}_{2} \mathrm{O}$; the sulfidic $\mathrm{Ni}$ extraction (Step II) effectively removed $\mathrm{Ni}_{3} \mathrm{~S}_{2}$; and the $\mathrm{Ni}^{0}$ extraction (Step III) removed most but not all the $\mathrm{Ni}^{0}$. Presented in Figure 6 are the XANES spectra of the three extraction residues. Similar spectra obtained on reagent-grade $\mathrm{NiSO}_{4} \cdot 6 \mathrm{H}_{2} \mathrm{O}, \mathrm{Ni}_{3} \mathrm{~S}_{2}, \mathrm{Ni}^{0}$, and "green" $\mathrm{NiO}$ were compared to the spectra obtained on the residues using a least-squares fitting technique to quantify Ni speciation. Quantitative XANES results for the soluble, sulfidic, and metallic Ni extraction residues are compared to expected Ni species proportions in Figures 7-9. The expected compositions were calculated assuming that the first three extraction steps selectively and quantitatively removed $\mathrm{NiSO}_{4} \cdot 6 \mathrm{H}_{2} \mathrm{O}, \mathrm{Ni}_{3} \mathrm{~S}_{2}$, and $\mathrm{Ni}^{0}$. XANES measurements of $\mathrm{Ni}^{0}$ and $\mathrm{NiO}$ concentrations in Figures 7-9 compare favorably to the corresponding calculated concentrations, with relative percent differences of $\leq 14 \%$. The XANES estimate of the $\mathrm{Ni}_{3} \mathrm{~S}_{2}$ proportion in the soluble Ni extraction residue, however, is $25 \%$ less than expected. XANES results in Figures 7-9 indicate that the first three extraction steps were effective in removing $\mathrm{NiSO}_{4} \cdot 6 \mathrm{H}_{2} \mathrm{O}, \mathrm{Ni}_{3} \mathrm{~S}_{2}$, and Ni${ }^{0}$, respectively. Similar to the Ni recovery results in Figure 2 and Table A-1, the XANES results suggest that the extraction procedure underestimated sulfidic Ni. However, contrary to the $\mathrm{Ni}$ recovery results in Figure 2, XANES results indicate that the extraction procedure did not significantly overestimate $\mathrm{Ni}^{0}$ contents. This implies, assuming that the XANES analysis of $\mathrm{Ni}_{3} \mathrm{~S}_{2}$ is accurate, that the soluble $\mathrm{Ni}$ extraction removed a portion of $\mathrm{Ni}_{3} \mathrm{~S}_{2}$ in addition to $\mathrm{NiSO}_{4} \cdot 6 \mathrm{H}_{2} \mathrm{O}$.

\subsection{NIST SRM 1648 (Urban TSP)}

\subsubsection{Sequential Ni Extraction Analysis}

In addition to the known Ni compound mixtures, SRM 1648 was analyzed in quadruplicate (approximately 16-mg samples) using the four-step sequential Ni extraction method. Extraction results are summarized in Figure 10 and additional extraction data are presented in Tables A-2 and A-3. Total Ni recoveries, based on the NIST certified Ni concentration of $82 \mu \mathrm{g} / \mathrm{g}$, were acceptable

with values ranging from $86 \%$ to $100 \%$ and averaging $92 \%$. The results in Figure 10 indicate that 


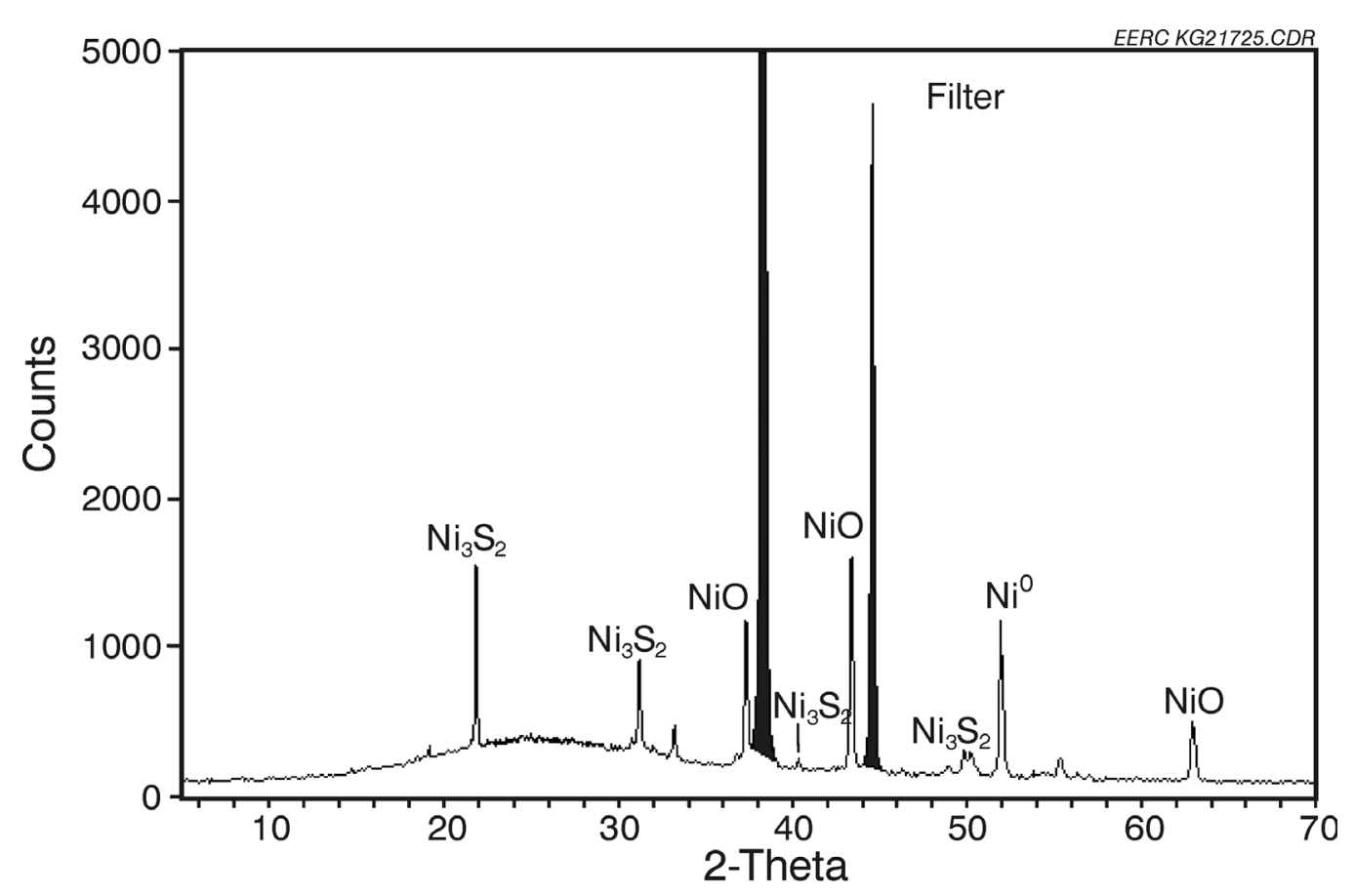

Figure 3. XRD pattern of soluble Ni extraction residue prepared from a standard $\mathrm{NiSO}_{4} 6 \mathrm{H}_{2} \mathrm{O}-\mathrm{Ni}_{3} \mathrm{~S}_{2}-\mathrm{Ni}^{0}-\mathrm{NiO}$ compound mixture.

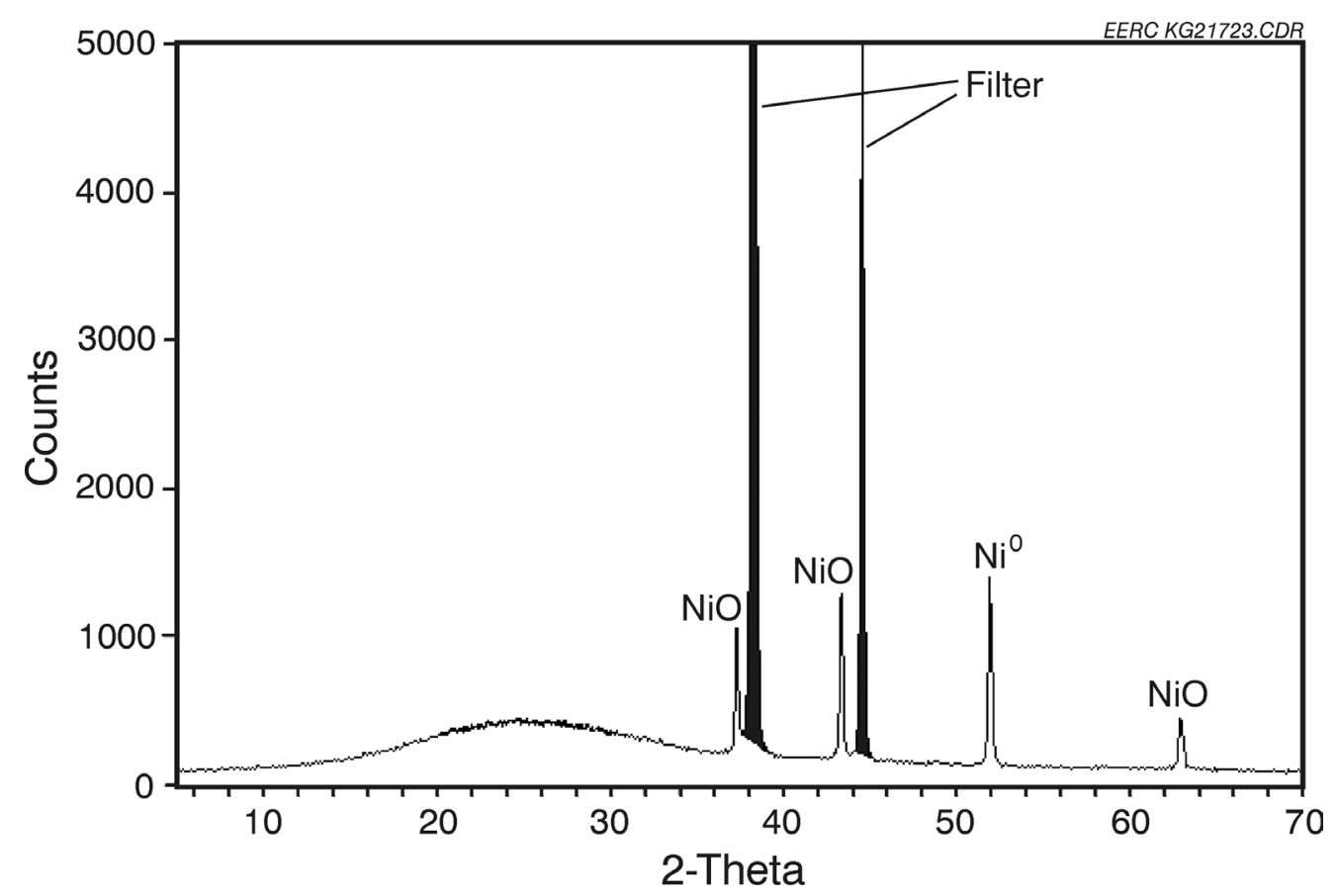

Figure 4. XRD pattern of sulfidic Ni extraction residue prepared from a standard $\mathrm{NiSO}_{4}$. $6 \mathrm{H}_{2} \mathrm{O}-\mathrm{Ni}_{3} \mathrm{~S}_{2}-\mathrm{Ni}^{0}-\mathrm{NiO}$ compound mixture. 


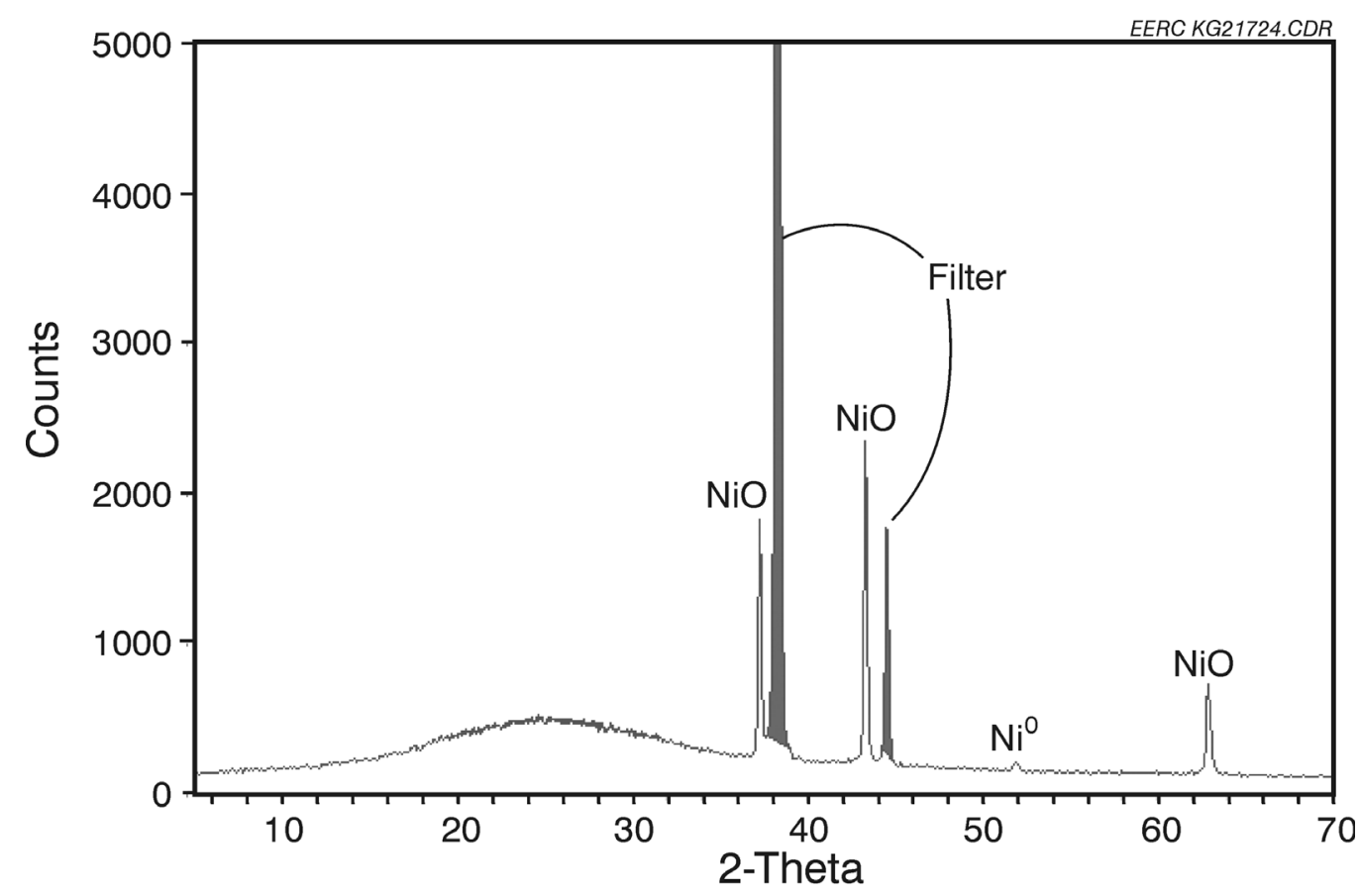

Figure 5. XRD pattern of $\mathrm{Ni}^{0}$ extraction residue prepared from a standard $\mathrm{NiSO}_{4} \cdot$ $6 \mathrm{H}_{2} \mathrm{O}-\mathrm{Ni}_{3} \mathrm{~S}_{2}-\mathrm{Ni}^{0}-\mathrm{NiO}$ compound mixture.

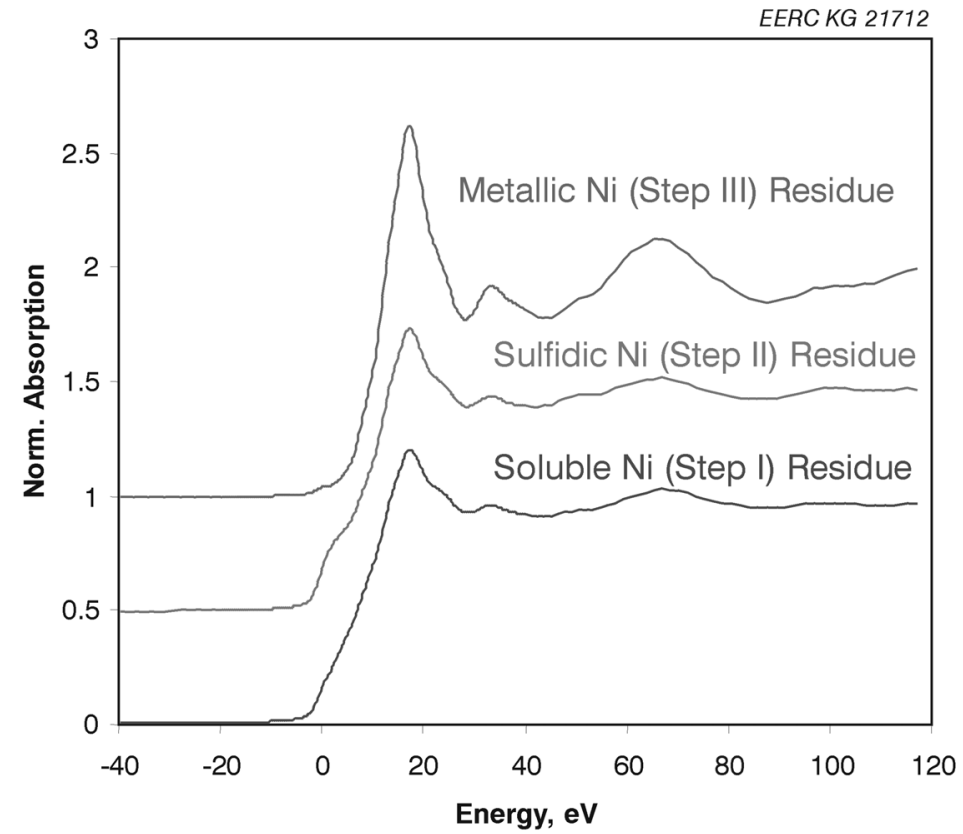

Figure 6. Ni K-edge XANES spectra of three Ni extraction residues prepared from a standard $\mathrm{Ni}$ compound mixture. Value of 0 on the abscissa corresponds to the actual Ni K-edge absorption energy of $8333 \mathrm{eV}$. 


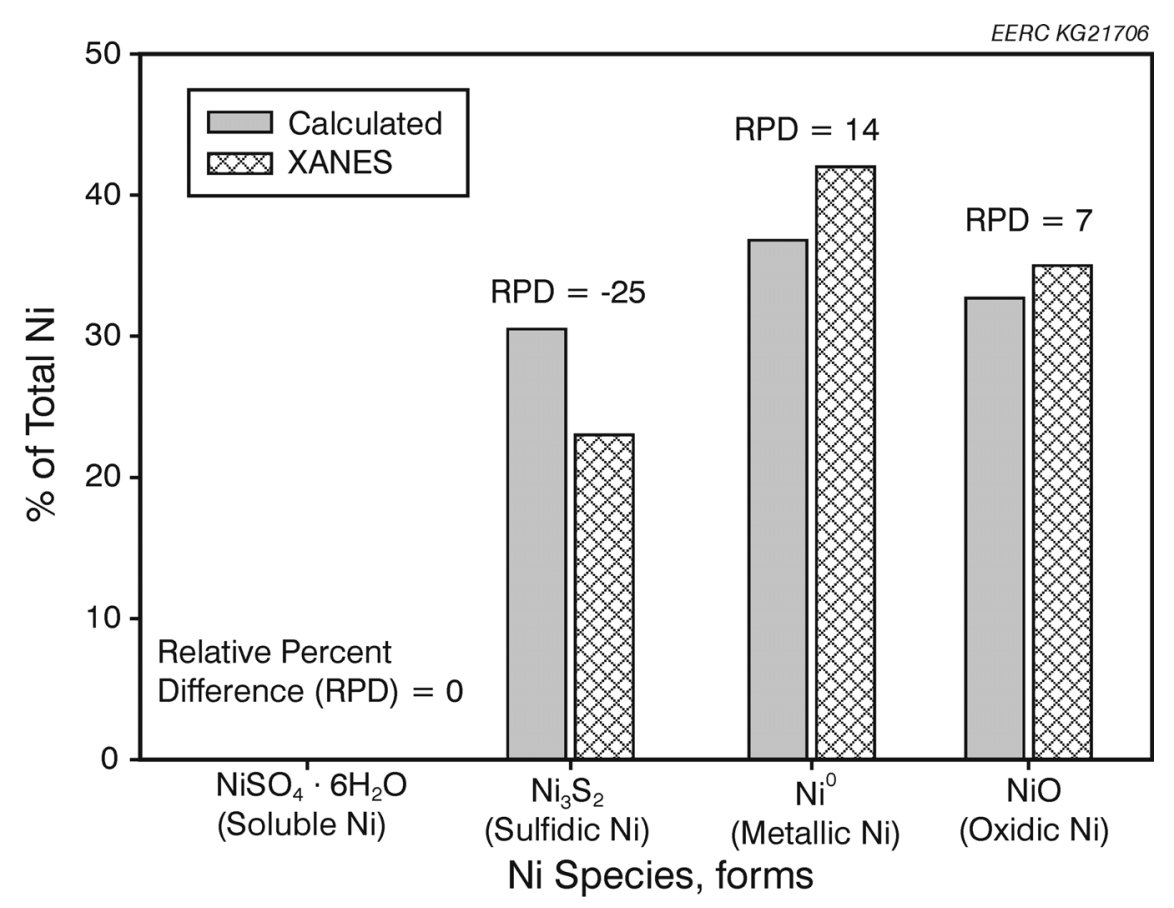

Figure 7. Comparison of calculated and measured (XANES) soluble Ni extraction residue speciation.

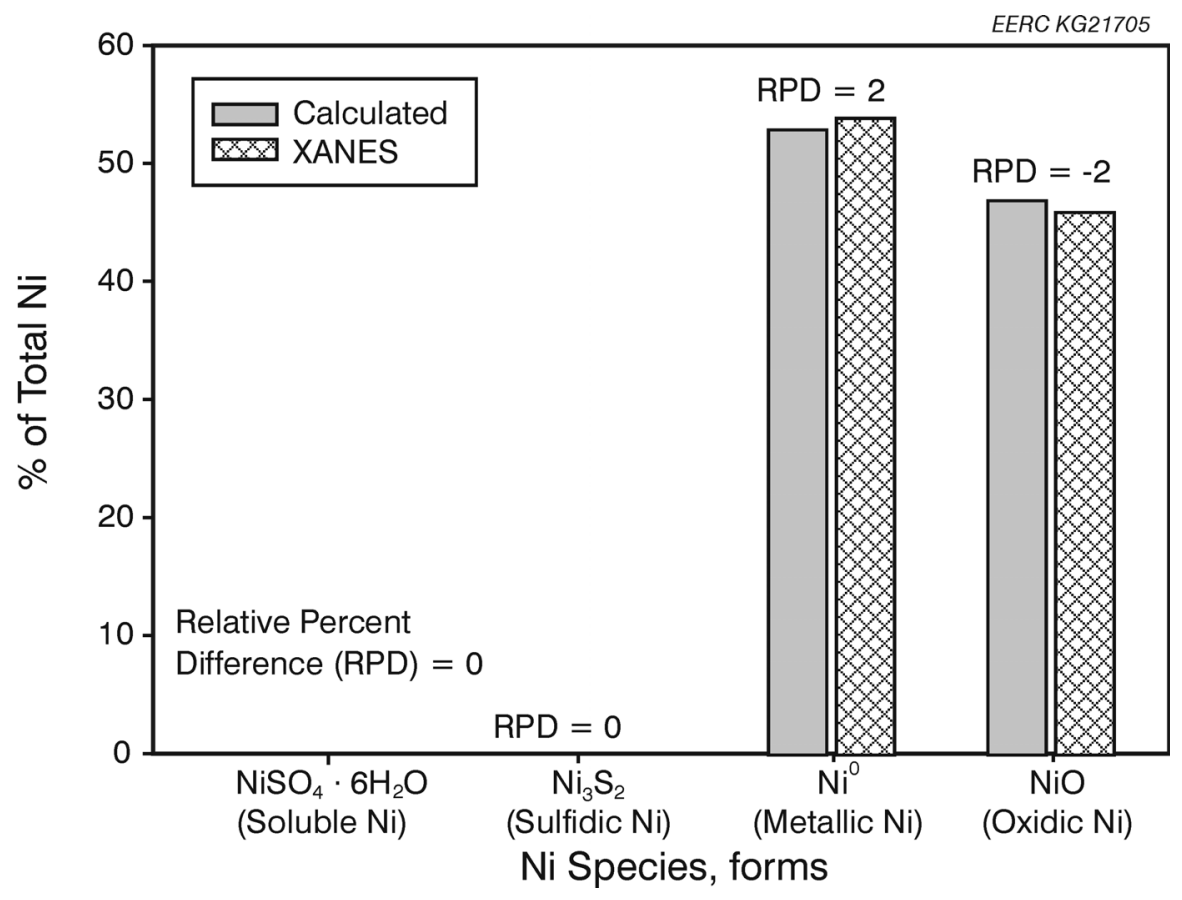

Figure 8. Comparison of calculated and measured (XANES) sulfidic Ni extraction residue speciation. 


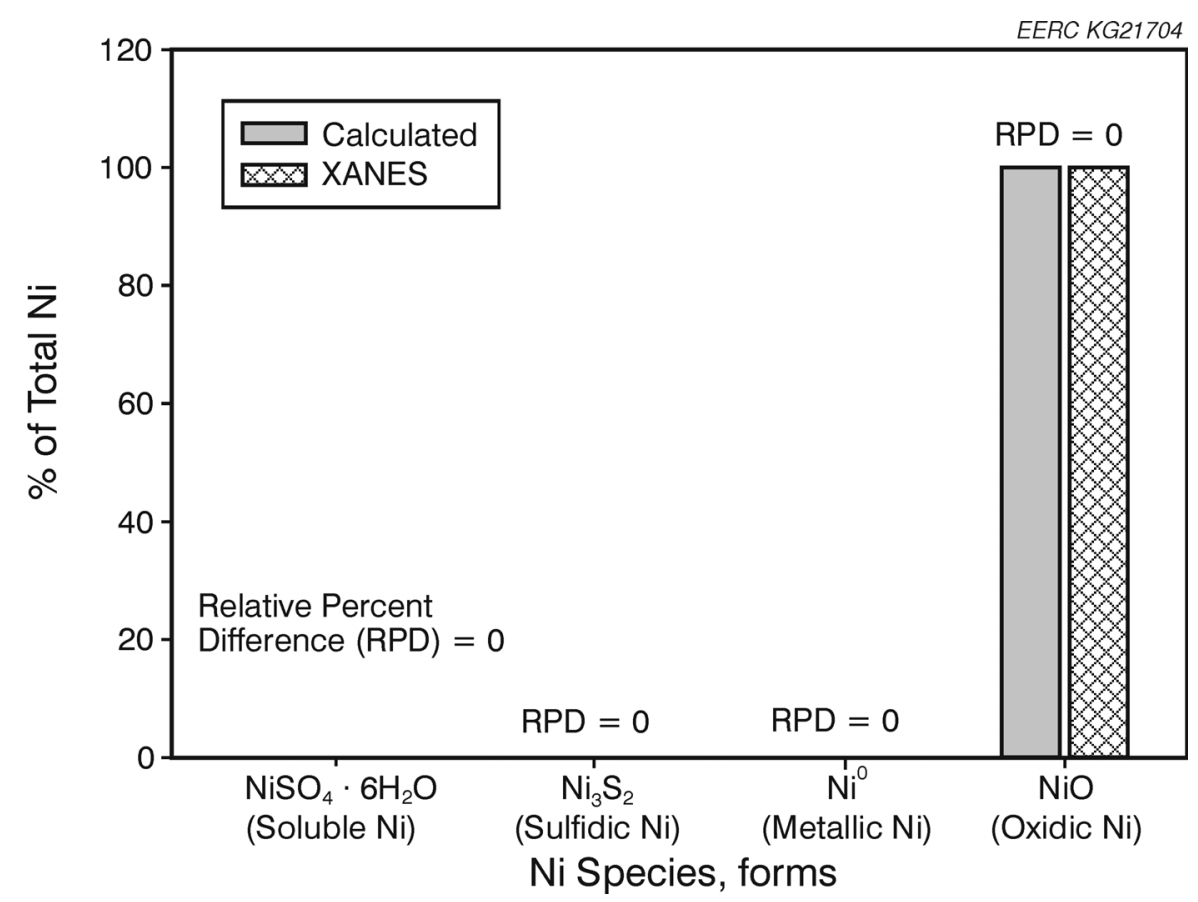

Figure 9. Comparison of calculated and measured (XANES) $\mathrm{Ni}^{0}$ extraction residue speciation.

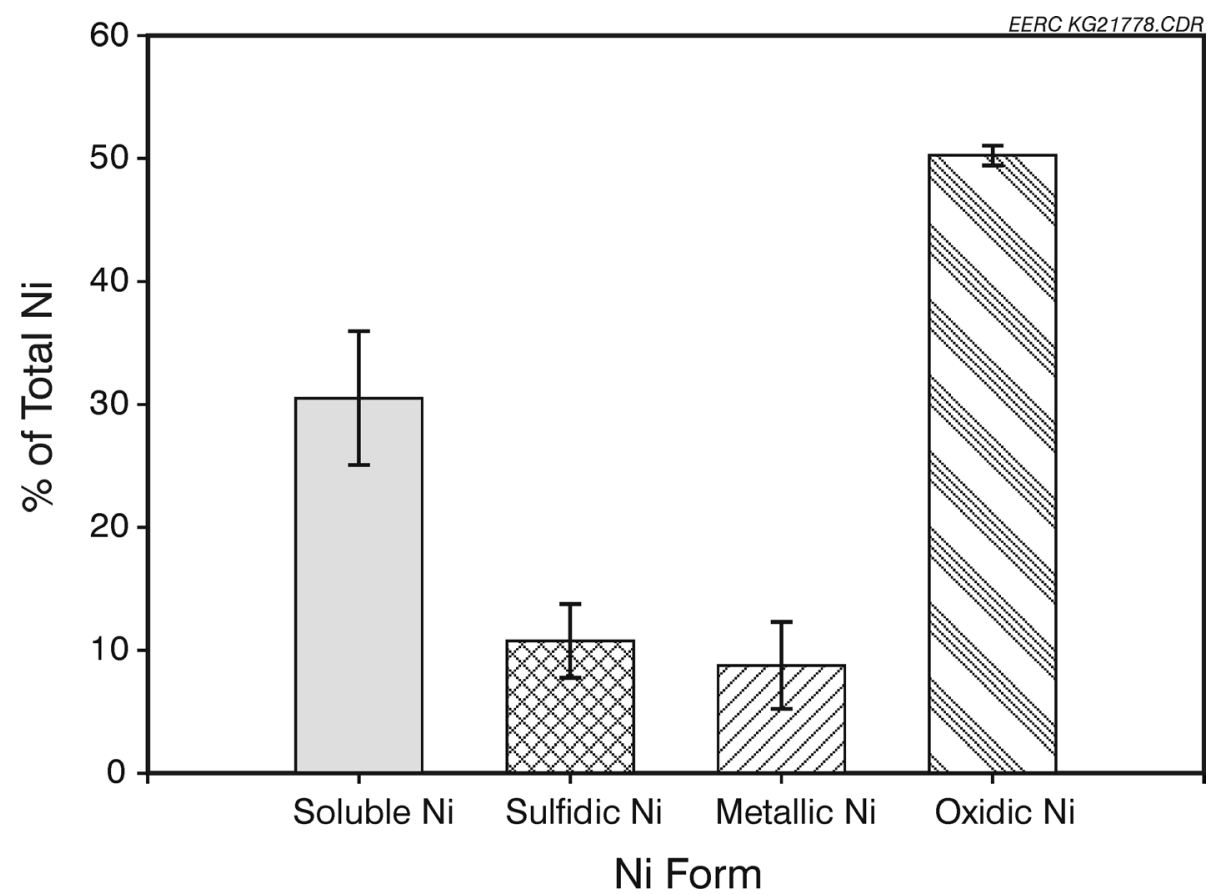

Figure 10. Mean Ni extraction results for SRM 1648. The error bars represent $\pm 95 \%$ confidence limits calculated from four sequential $\mathrm{Ni}$ extraction measurements. 
soluble and oxidic Ni forms account for about $80 \%$ of the total Ni in SRM 1648 and sulfidic and metallic Ni forms account for $20 \%$ of the remaining Ni.

\subsubsection{XAFS Spectroscopy Analysis}

Three extraction (Steps I-III) residues from SRM 1648 were analyzed using XAFS spectroscopy. However, the quality (signal-to-noise ratio) of the XAFS spectra obtained on the three residues was insufficient for processing and analysis. Mass balance calculations, based on the certified Ni content of SRM 1648, the extraction results presented in Figure 10, and GFAAS analyses of the residues, indicated that $\mathrm{Ni}$ was present in concentrations (41-57 ppm) well above the XAFS spectroscopy detection limit of $\sim 5 \mathrm{ppm}$. Apparently, the residue samples were too sparsely distributed on the filter substrate to obtain high-quality XAFS spectra. Visual inspection of the filters indicated that the residues were not homogeneously distributed which probably also contributed to the lack of XAFS spectroscopy sensitivity.

\subsection{Urban (Davie, Florida) TSP, $\mathbf{P M}_{10}$, and $\mathbf{P M}_{2.5}$}

\subsubsection{Mass Loadings and Ni Concentrations}

Filter mass loading information, exemplified in Table 2 for the TSP sample, was used to calculate average concentrations of airborne TSP, $\mathrm{PM}_{10}$, and $\mathrm{PM}_{2.5}$ of $26.8,10.4$, and $6.3 \mu \mathrm{g} / \mathrm{m}^{3}$, respectively. Compared in Table 3 are the average measured (in duplicate) and certified Ni concentrations for SRM 1648 and Ni concentrations for a filter blank and TSP collected at the Davie, Florida, site. The measured Ni concentration for the SRM 1648 is biased 22\% high relative to the NIST-certified Ni concentration. The filter blank contained significant Ni but was much less than the Ni concentration of Davie TSP. The Ni concentration of Davie TSP is apparently much greater than SRM 1648. However, after the Ni contamination in the filter blank is accounted for and it is assumed that, similar to SRM 1648 the Ni measurement is biased 22\% high, the corrected Ni concentration of Davie TSP presented in Table 3 is very similar to SRM 1648 Ni concentration.

Table 2. High-Volume Aerosol Sampling Parameters

\begin{tabular}{lc}
\hline Parameter & Value \\
\hline Filter Weight, initial & $4.43 \mathrm{~g}$ \\
Filter Weight, final & $4.69 \mathrm{~g}$ \\
Filter Loading & $0.26 \mathrm{~g}$ \\
Total Sample Volume & $9,700 \mathrm{~m}^{3}$ \\
TSP & $26.8 \mu \mathrm{g} / \mathrm{m}^{3}$ \\
\hline
\end{tabular}


Table 3. Comparison of SRM 1648 and Davie TSP Ni Concentrations, ppm

\begin{tabular}{|c|c|c|c|c|c|c|}
\hline & \multicolumn{3}{|c|}{ NIST SRM 1648} & \multicolumn{3}{|c|}{ Davie, Florida } \\
\hline & Measured & $\begin{array}{c}\text { NIST } \\
\text { Certified }\end{array}$ & $\mathrm{RPD}^{1}$ & $\begin{array}{l}\text { Filter } \\
\text { Blank }\end{array}$ & $\begin{array}{c}\text { Urban TSP and } \\
\text { Filter }\end{array}$ & Urban $\mathrm{TSP}^{2}$ \\
\hline $\mathrm{Ni}$ & 100 & 82 & 22 & 31 & 150 & 86 \\
\hline
\end{tabular}

\subsubsection{XRD Analysis}

A blank HVAS filter and the HVAS filter from Davie were analyzed using XRD to identify crystalline components of PM. The XRD pattern presented in Figure 11 indicates that halite $(\mathrm{NaCl})$ and calcite $\left(\mathrm{CaCO}_{3}\right)$ are present in Davie TSP. Halite and calcite are known tracers of marine aerosols. The broad, diffuse peak, ranging from about $14^{\circ}$ to $36^{\circ} 2 \theta$, indicates that the TSP is composed largely of amorphous or crystallite $(<0.1 \mu \mathrm{m}$ in diameter $)$ components.

\subsubsection{Sequential Ni Extraction Analysis}

Assuming a uniform distribution of TSP, the HVAS filter was sectioned into equal portions for subsequent sequential $\mathrm{Ni}$ extraction analysis, with each portion representing approximately $22 \mathrm{mg}$ of TSP. Sequential Ni extraction was performed in duplicate on two TSP sections. Method blanks were also analyzed, and all blank results were below GFAAS detection. Presented in Figure 12 are four-step Ni extraction results for the urban TSP collected in Davie, Florida. These

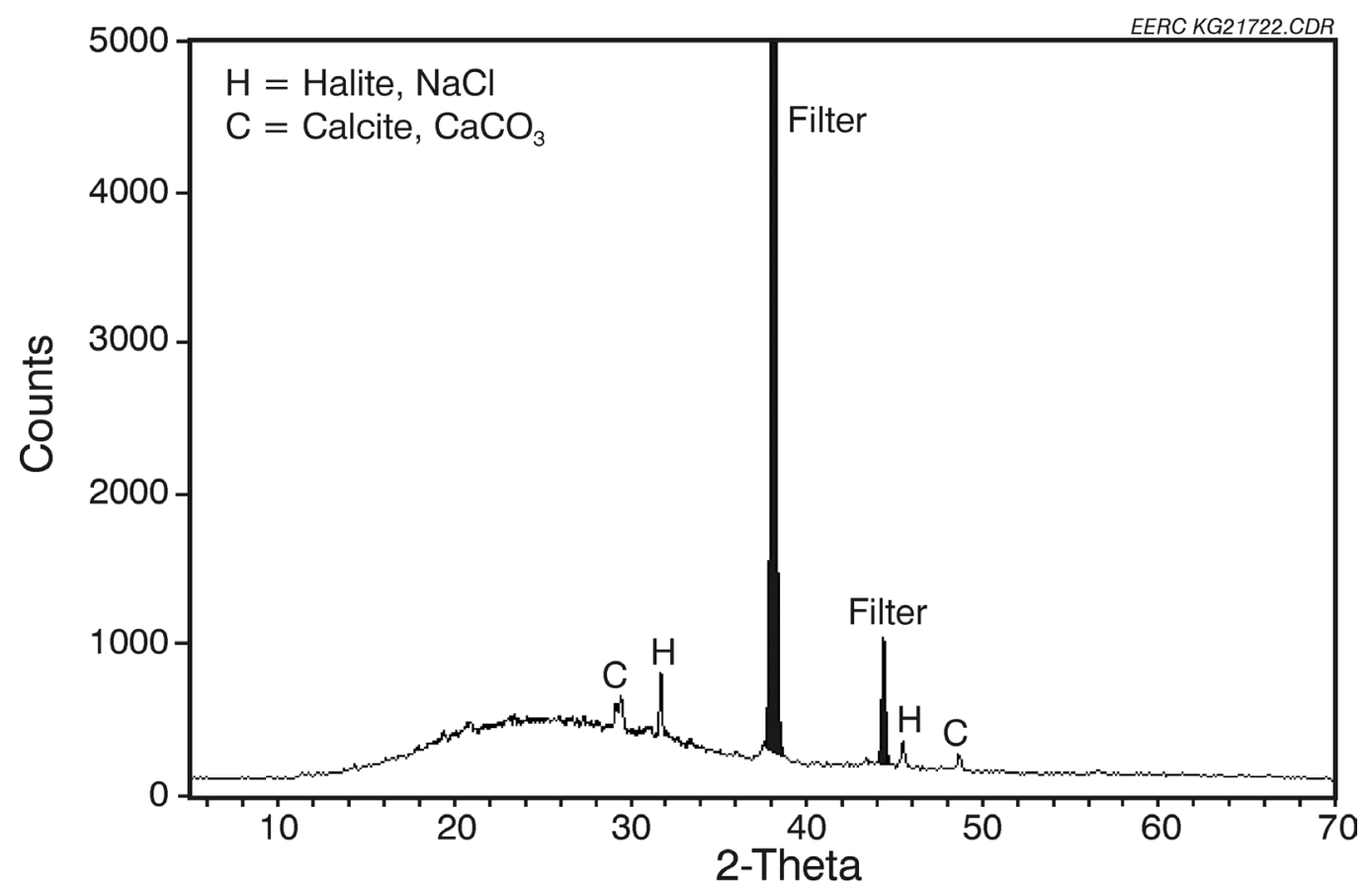

Figure 11. XRD pattern of HVAS filter containing TSP from Davie, Florida. 


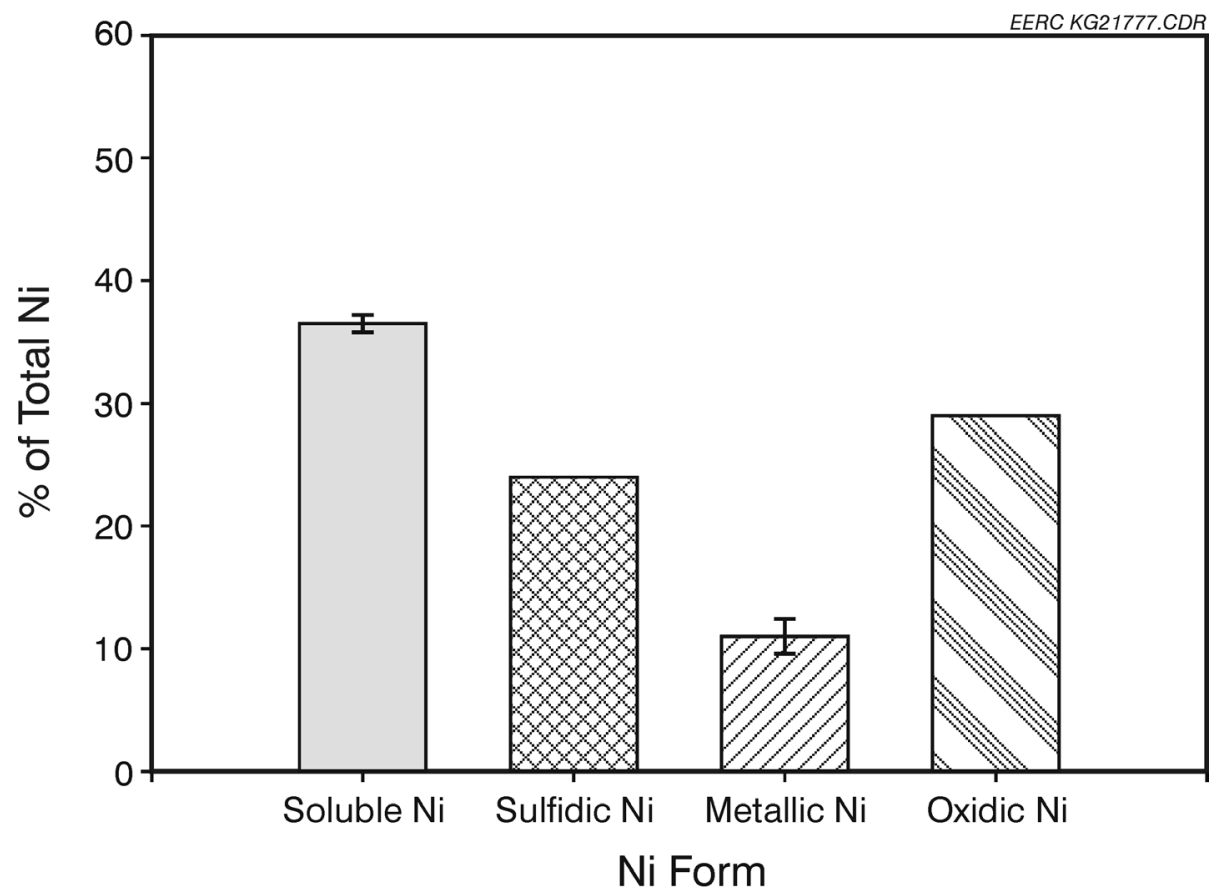

Figure 12. Average of duplicate Ni extraction results for urban TSP collected in Davie, Florida.

extraction results indicate that soluble, oxidic, and sulfidic Ni forms account for most of the $\mathrm{Ni}$ in Davie TSP. $\mathrm{Ni}^{0}$ accounts for about $10 \%$ of the remaining total $\mathrm{Ni}$. In comparison to SRM 1648 (Figure 10), Davie TSP contains much greater proportions of soluble- and sulfidic-Ni and less oxidic Ni.

\subsubsection{Sulfur K-Edge XAFS Spectroscopy Analyses}

Presented in Figure 13 are unprocessed sulfur K-edge XAFS spectra for the ACCU $\left(\mathrm{PM}_{10}\right)$ and SAS $\left(\mathrm{PM}_{2.5}\right)$ filter blanks and filters containing Davie TSP, $\mathrm{PM}_{10}$, and $\mathrm{PM}_{2.5}$. A spectrum for a blank filter from the HVAS is not presented in Figure 13 because it was inadvertently not analyzed for sulfur using XAFS spectroscopy. Although the $\mathrm{PM}_{10^{-}}$and $\mathrm{PM}_{2.5}$-containing filters exhibit much smaller x-ray absorption intensities than the TSP-containing filter, the absorption intensities for these samples are significantly greater than the absorption signals for the corresponding blank filters. Hence, the sulfur absorptions are primarily caused by the $\mathrm{PM}_{10}$ and $\mathrm{PM}_{2.5}$ trapped within the filters. Sulfur XANES spectra for the SAS filter blank and the filters containing TSP, $\mathrm{PM}_{10}$, and $\mathrm{PM}_{2.5}$ are presented in Figure 14. An XANES spectrum for the ACCU filter blank is not included in Figure 14 because the sulfur K-edge absorption signal was too weak to be processed. The XANES features in Figure 14 are insensitive to differences in sulfur concentration because of the data reduction process used to create the XANES spectra. The energy location of the sulfur peaks in Figure 14 are all consistent with the presence of the sulfate $\left(\mathrm{SO}_{4}\right)$ species. The XANES sulfur species detection limit is approximately $3 \%$ of the total sulfur present, thus $>97 \%$ of the sulfur in Davie TSP, $\mathrm{PM}_{10}$, $\mathrm{PM}_{2.5}$, and SAS filter blank is present as $\mathrm{SO}_{4}$-based compounds. An ion chromatography analysis of the Step I and II (Table 1) extracts from Davie TSP indicated that it contains $1.61 \mathrm{wt} \% \mathrm{SO}_{4}$. 


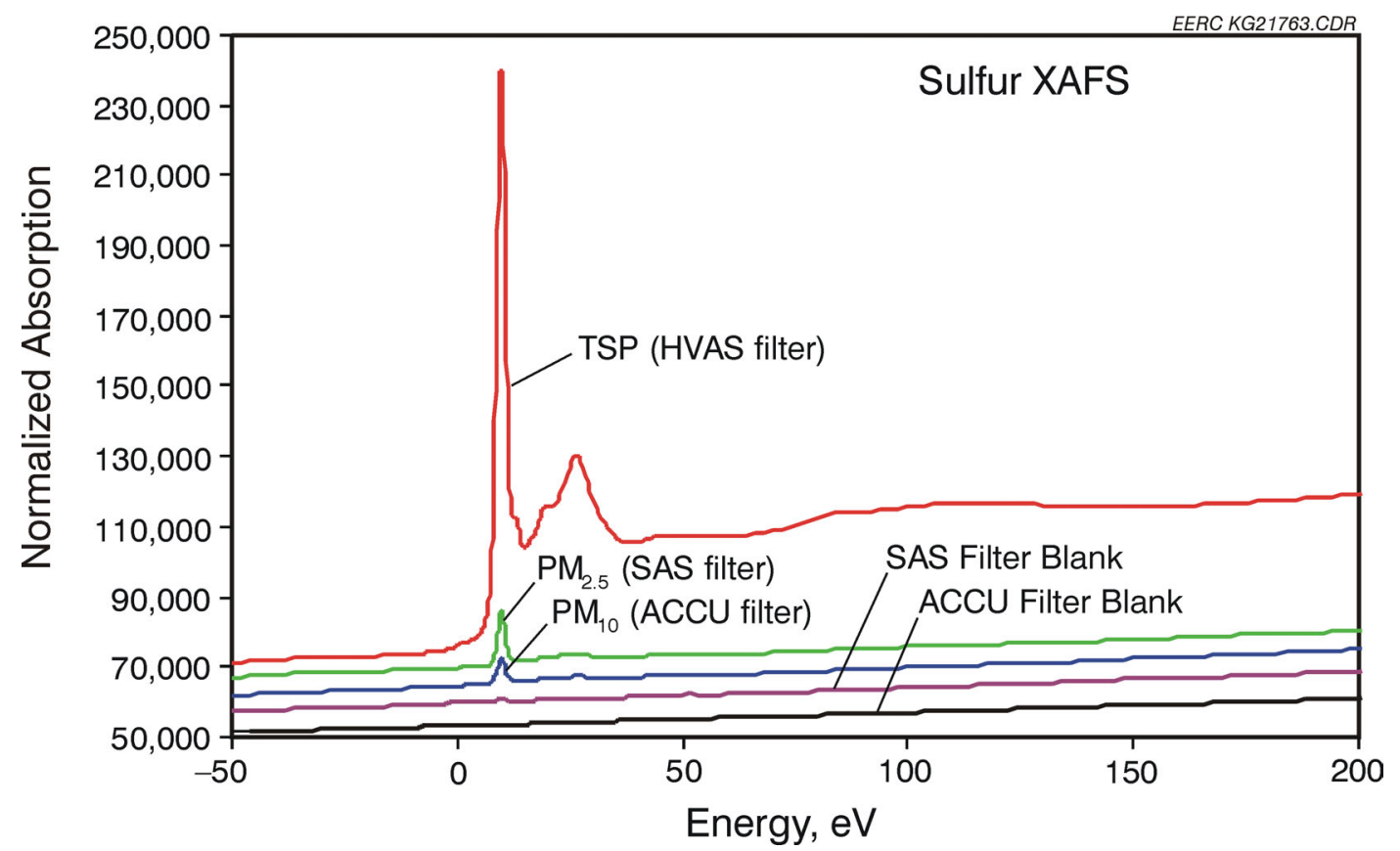

Figure 13. Sulfur K-edge XAFS spectra of ACCU $\left(\mathrm{PM}_{10}\right)$ and SAS $\left(\mathrm{PM}_{2.5}\right)$ filter blanks and filters containing Davie TSP, $\mathrm{PM}_{10}$, and $\mathrm{PM}_{2.5}$. Value of 0 on the abscissa corresponds to the actual sulfur K-edge absorption energy of $2472 \mathrm{eV}$.

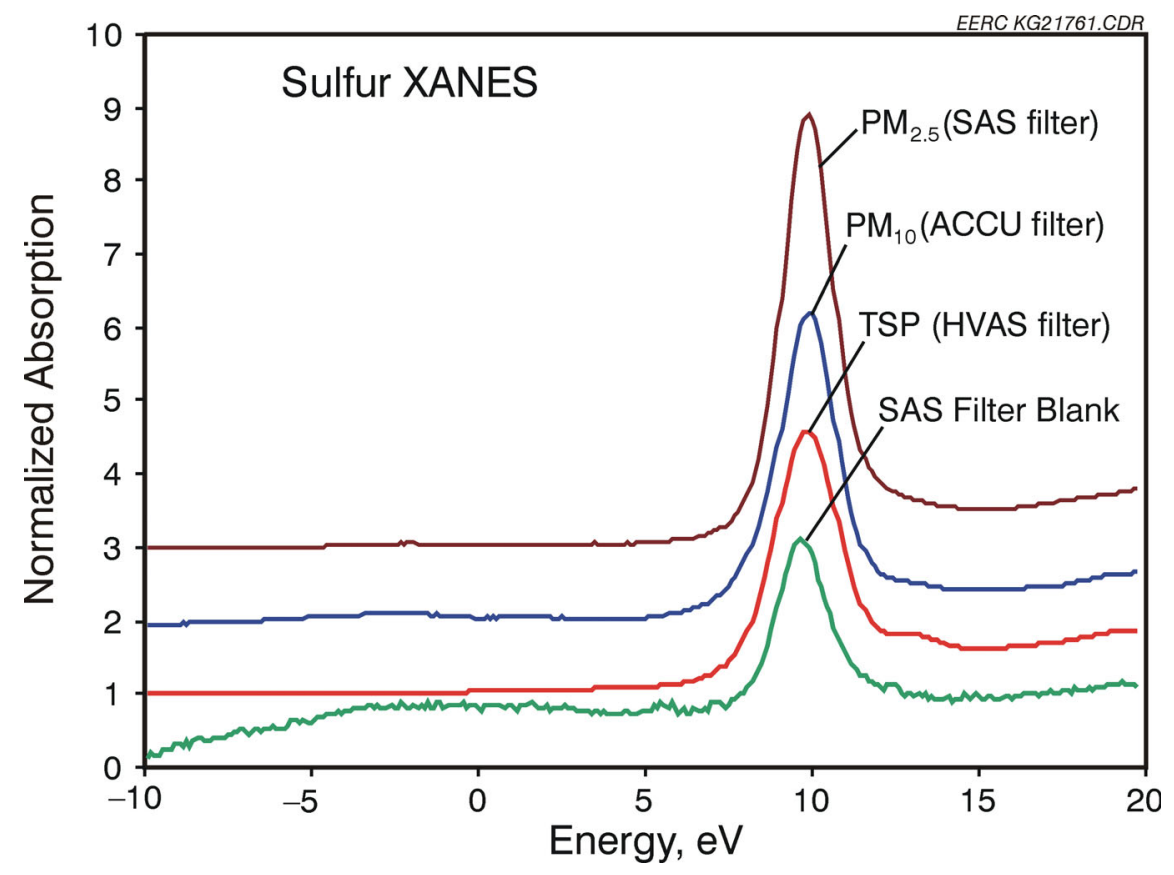

Figure 14. Sulfur XANES spectra of SAS filter blank and filters containing Davie TSP, $\mathrm{PM}_{10}$, and $\mathrm{PM}_{2.5}$. Value of 0 on the abscissa corresponds to the actual S K-edge absorption energy of $2472 \mathrm{eV}$. 


\subsubsection{Nickel K-Edge XAFS Spectroscopy Analyses}

Presented in Figure 15 are Ni K-edge XAFS spectra for the HVAS (TSP), ACCU $\left(\mathrm{PM}_{10}\right)$, and SAS $\left(\mathrm{PM}_{2.5}\right)$ filter blanks and filters containing Davie TSP, $\mathrm{PM}_{10}$, and $\mathrm{PM}_{2.5}$. Also included in Figure 15 is a Ni K-edge XAFS spectrum collected when no sample was in the x-ray beam path. The relative $\mathrm{Ni}$ absorption intensity relationships are $\mathrm{PM}_{10}>\mathrm{TSP}>\mathrm{PM}_{2.5} \cong$ filter and beam blanks indicating that $\mathrm{Ni}$ is mostly concentrated in $\mathrm{PM}_{10}$. Duplicate GFAAS analyses of Davie TSP indicated that it contains $86 \mathrm{ppm} \mathrm{Ni}$ (Table 3). $\mathrm{Ni}$ absorption is generally proportional to $\mathrm{Ni}$ concentration; thus the Davie $\mathrm{PM}_{10}$ sample is estimated to contain approximately $140 \mathrm{ppm} \mathrm{Ni}$. These Davie TSP and $\mathrm{PM}_{10} \mathrm{Ni}$ concentrations correspond to airborne Ni concentrations of 2.3 and $1.5 \mathrm{ng} / \mathrm{m}^{3}$, respectively, which are very similar to the annual average ambient $\mathrm{Ni}$ concentration of $1.9 \mathrm{ng} / \mathrm{m}^{3}$ estimated for Broward County by EPA. ${ }^{37}$ These Ni concentrations are much lower in comparison to average urban ambient air Ni concentrations which range from 5 to $50 \mathrm{ng} / \mathrm{m}^{3}$ and are more representative of $\mathrm{Ni}$ concentrations found in remote and rural areas. ${ }^{9-12}$ The low airborne $\mathrm{Ni}$ concentrations at the Davie, Florida, air-monitoring site probably represent the atmospheric burden of "background" Ni derived from long-range transport via the southeast and easterly North Atlantic trade winds (Figure 1).

The Ni K-edge absorption signals from the filters containing Davie TSP and $\mathrm{PM}_{10}$ were sufficiently intense to process and create the XANES spectra presented in Figure 16. Spectra from the Ni XANES database, described previously in the experimental section of this report, were compared to the spectra shown in Figure 16 using a least-squares fitting procedure. Estimates, based

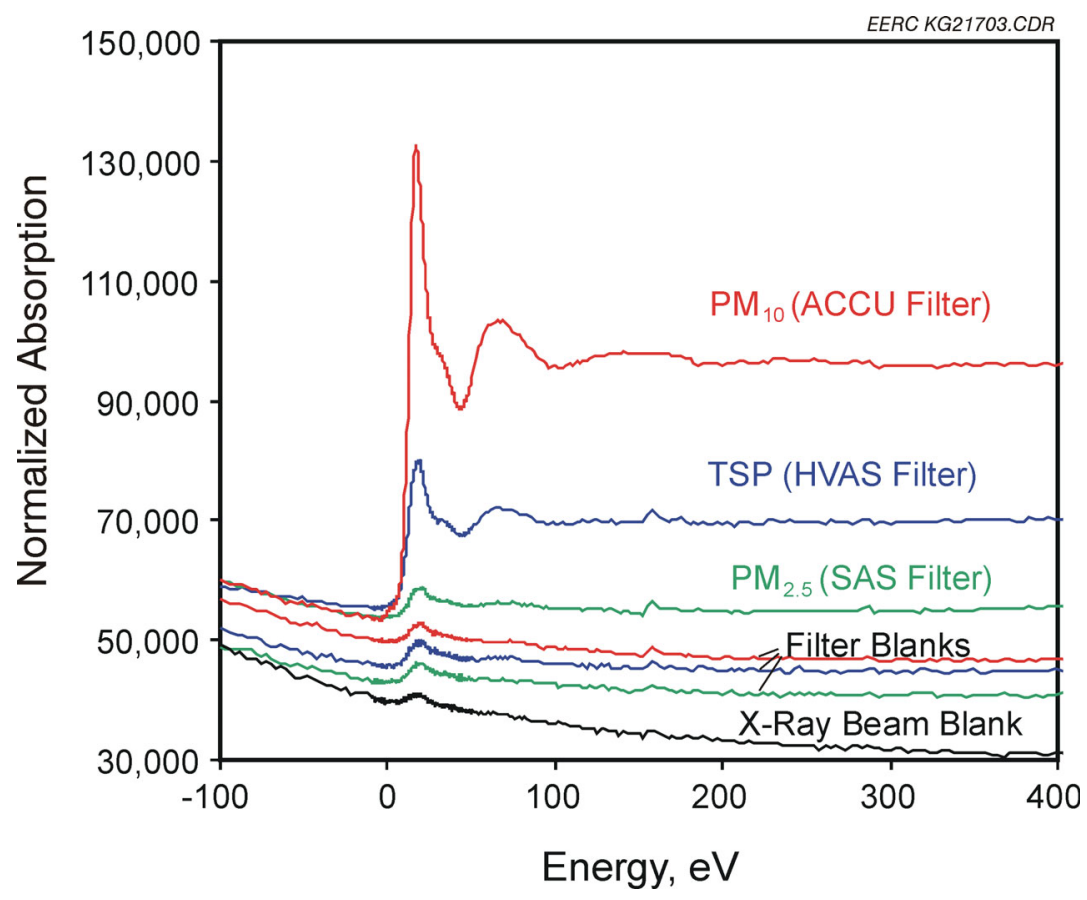

Figure 15. Ni K-edge XAFS spectra of HVAS, ACCU, and SAS filter blanks and filters containing Davie TSP, $\mathrm{PM}_{10}$, and $\mathrm{PM}_{2.5}$. Value of 0 on the abscissa corresponds to the actual $\mathrm{Ni}$ K-edge absorption energy of $8333 \mathrm{eV}$. 


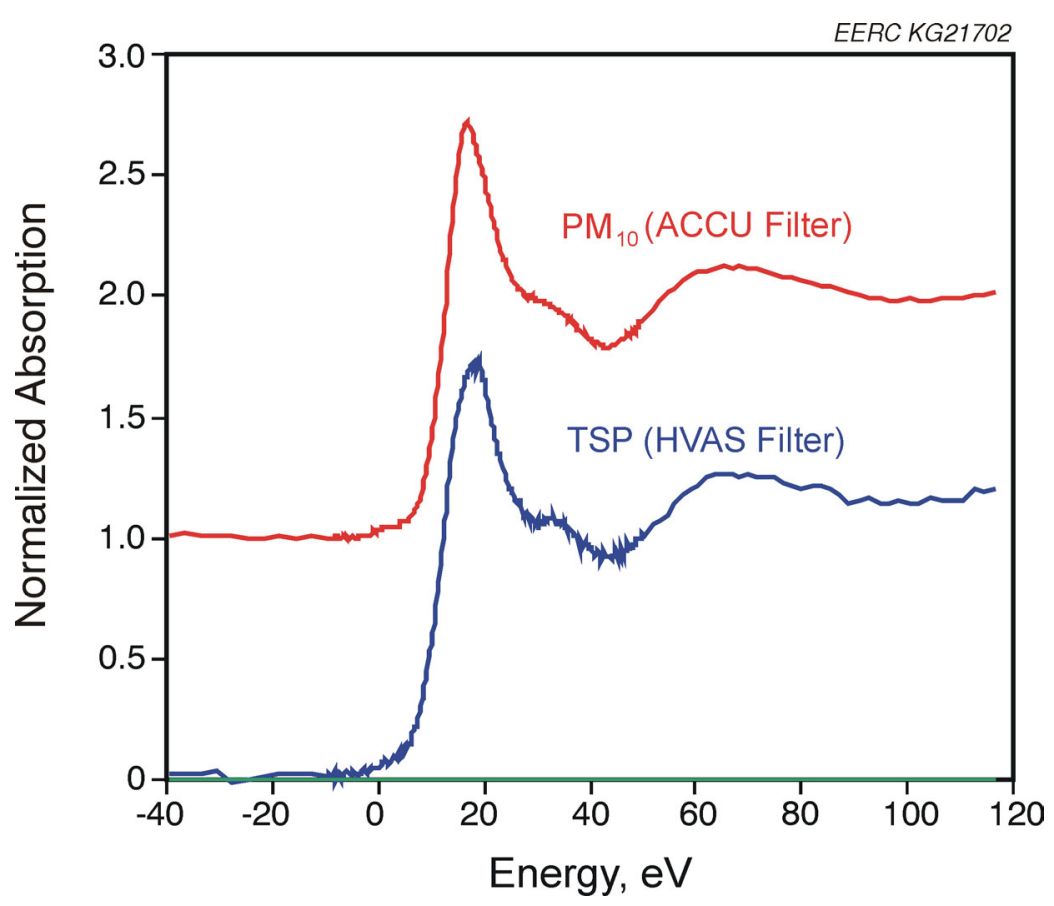

Figure 16. Ni K-edge XANES spectra of the filters containing Davie TSP and $\mathrm{PM}_{10}$. Value of 0 on the abscissa corresponds to the actual Ni K-edge absorption energy of $8333 \mathrm{eV}$.

on the least-squares fitting, of the Ni species compositions of Davie TSP and $\mathrm{PM}_{10}$ are provided in Table 4. Davie $\mathrm{PM}_{10}$ contains a much greater proportion of $\mathrm{NiSO}_{4} \cdot \mathrm{xH}_{2} \mathrm{O}$ relative to TSP, probably because of the greater surface area of $\mathrm{PM}_{10}$ on which $\mathrm{NiSO}_{4} \cdot \mathrm{xH}_{2} \mathrm{O}$ heterogeneously condensed or adsorbed.

Table 4. XANES Ni Speciation Results for Davie TSP and $\mathrm{PM}_{10}$ \% of total Ni

\begin{tabular}{lcc}
\hline $\mathrm{Ni}$ Species & $\mathrm{TSP}$ & $\mathrm{PM}_{10}$ \\
\hline $\mathrm{NiSO}_{4} \cdot \mathrm{xH}_{2} \mathrm{O}$ & 40 & 78 \\
$\mathrm{NiFe}_{2} \mathrm{O}_{4}$ & 50 & 22 \\
$\mathrm{NiS}$ & 10 & $<5$ \\
\hline
\end{tabular}

The Ni speciation results in Table 4 were used to calculate the concentrations of $\mathrm{Ni}$ compounds in Davie TSP and $\mathrm{PM}_{10}$ and ambient air. The calculations were performed assuming pure stoichiometric nickel hexahydrite $\left(\mathrm{NiSO}_{4} \cdot 6 \mathrm{H}_{2} \mathrm{O}\right), \mathrm{NiFe}_{2} \mathrm{O}_{4}$, and $\mathrm{NiS}$ compounds. Results of the calculations are presented in Table 5. The results in Table 5, especially those for $\mathrm{PM}_{10}$, can be used to estimate an inhalation dose and are, therefore, more useful than those in Table 4 for evaluating the potential health risks associated with individual Ni species. 
Table 5. Ni Species Concentrations for Davie TSP and $\mathbf{P M}_{10}$, ppm

\begin{tabular}{lccccc}
\hline & \multicolumn{2}{c}{$\mathrm{TSP}$} & & \multicolumn{2}{c}{$\mathrm{PM}_{10}$} \\
\cline { 2 - 3 } \cline { 5 - 6 } Ni Species & ppm & $\mathrm{ng} / \mathrm{m}^{3}$ & & $\mathrm{ppm}$ & $\mathrm{ng} / \mathrm{m}^{3}$ \\
\hline $\mathrm{NiSO}_{4} \cdot 6 \mathrm{H}_{2} \mathrm{O}$ & 154 & 4.1 & & 489 & 5.1 \\
$\mathrm{NiFe}_{2} \mathrm{O}_{4}$ & 172 & 4.6 & & 123 & 1.3 \\
$\mathrm{NiS}$ & 13 & 0.4 & & $<11$ & $<0.1$ \\
\hline
\end{tabular}

Compared in Figure 17 are sequential Ni extraction and XANES analysis results for Davie TSP. The proportion of $\mathrm{NiSO}_{4} \cdot \mathrm{xH}_{2} \mathrm{O}$ in Davie TSP measured by XANES is similar to the proportion of soluble $\mathrm{Ni}$ measured by the $\mathrm{Ni}$ extraction method. In contrast to the four-step $\mathrm{Ni}$ extraction results for Davie TSP, the XANES results indicate a much lower proportion of sulfidic $\mathrm{Ni}$ as $\mathrm{NiS}$ and a much greater proportion of oxidic $\mathrm{Ni}$, possibly in the form of $\mathrm{NiFe}_{2} \mathrm{O}_{4}$. The XANES method did not detect any $\mathrm{Ni}^{0}$ which was estimated by the $\mathrm{Ni}$ extraction method to comprise about $10 \%$ of the total Ni. Contrary to XAFS spectroscopy results for the Ni compound mixture residue samples, these results suggest that oxidic Ni in Davie TSP was extracted during the sulfidic Ni and $\mathrm{Ni}^{0}$ (second and third) extraction steps rather than in the last step. Scanning electron microscopy analyses indicated that Ni-bearing particles in the model Ni compound mixture are much larger relative to those found in Davie TSP, suggesting that the sequential Ni extraction method overestimates sulfidic $\mathrm{Ni}$ and $\mathrm{Ni}^{0}$ fractions when smaller particles are present.

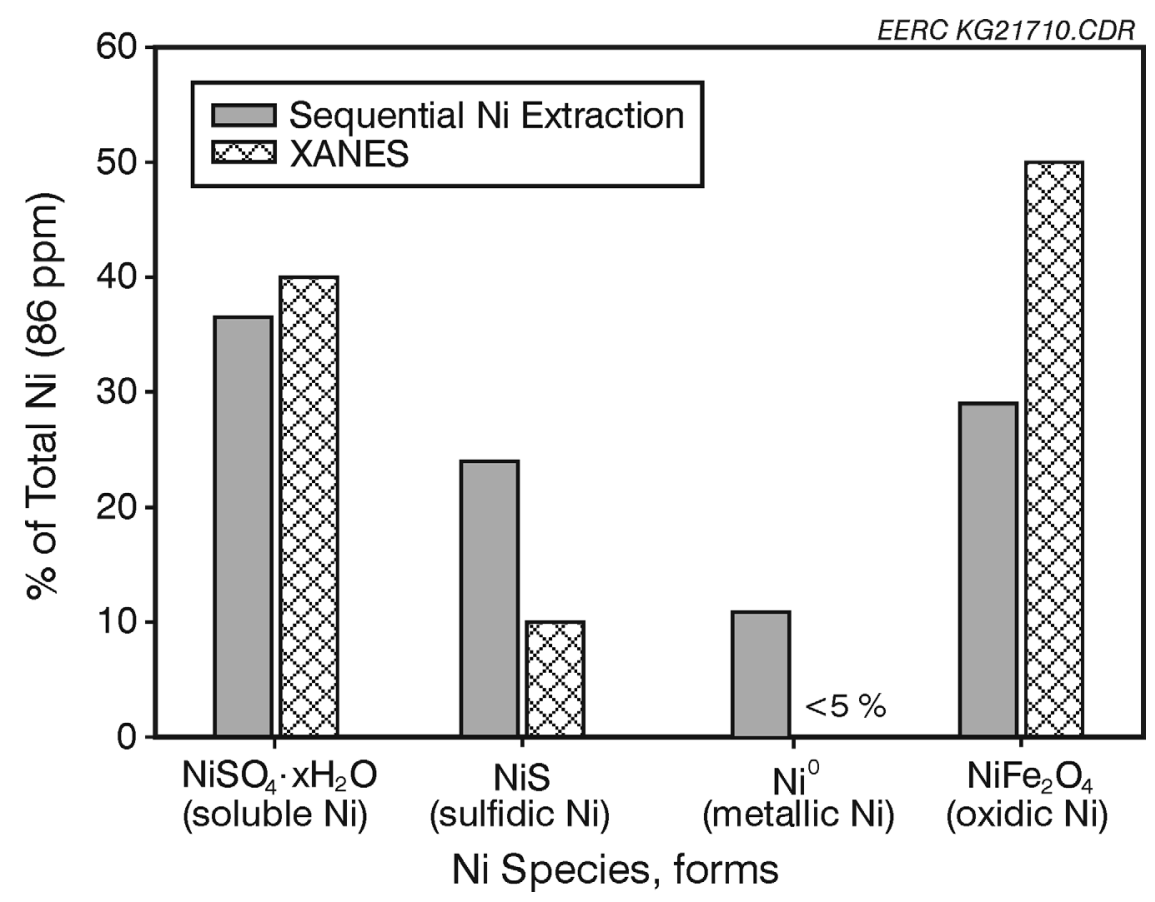

Figure 17. Comparison of sequential Ni extraction and XANES analysis results for Davie TSP. 
The soluble Ni extraction procedure (Table 1) was performed on a fliter blank and on a representative portion of the Davie TSP filter sample. Presented in Figure 18 are Ni K-edge XAFS spectra for an HVAS filter blank, an HVAS filter blank from the soluble Ni extraction, and Davie TSP residue from the soluble Ni extraction procedure. Spectra for both filter blanks are similar, and the Ni K-edge absorption signal for the Davie TSP residue is only about three times more intense relative to the corresponding filter blank. Consequently, spectral processing resulted in a poorquality XANES spectrum for the Davie TSP residue sample that was insufficient for quantitative analysis.

\subsubsection{ASEM}

Urban TSP deposited on portions of the carbon tape, corresponding to a daily time period of 8:00 a.m.-5:00 p.m., of the Burkard Seven-Day Recording Volumetric Spore Trap were analyzed using ASEM. Approximately 800-1100 particles were analyzed at random on the samples collected on August 27-30. Compared in Figure 19 are the number concentrations of Ni-bearing particles, arbitrarily defined as containing $\geq 10 \mathrm{wt} \% \mathrm{Ni}$, sampled during each of 4 days (August 27-30, 2002). Approximately $8 \%$ of the particles sampled on August 27,29 , and 30 contained $\geq 10 \mathrm{wt} \% \mathrm{Ni}$, whereas on August 28, about 15\% of the particles were Ni bearing. Apparently, additional emission sources of $\mathrm{Ni}$ were contributing to the TSP sample collected on August 28 or the Ni emission rate for a particular source in the Davie, Florida, area increased on August 28.

The particle-size distributions of Ni-bearing particles are compared in Figure 20. Most of the Ni-bearing particles are $<10 \mu \mathrm{m}$ in diameter, indicating that they were released from combustion

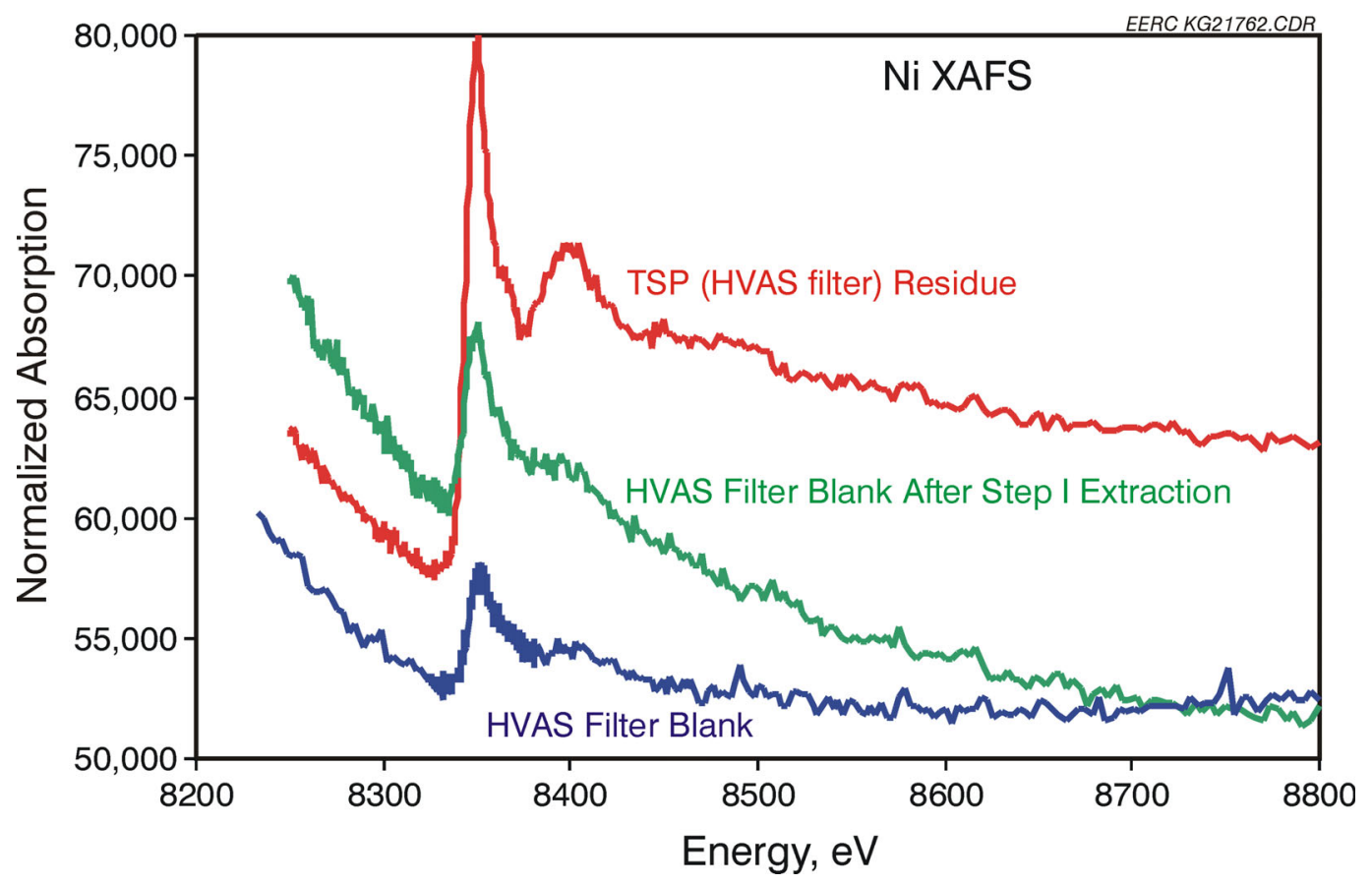

Figure 18. Ni K-edge XAFS spectra of a HVAS filter blank, HVAS filter blank from the soluble Ni (Step I) extraction, and a HVAS filter containing Davie TSP residue from the soluble Ni

(Step I) extraction. 


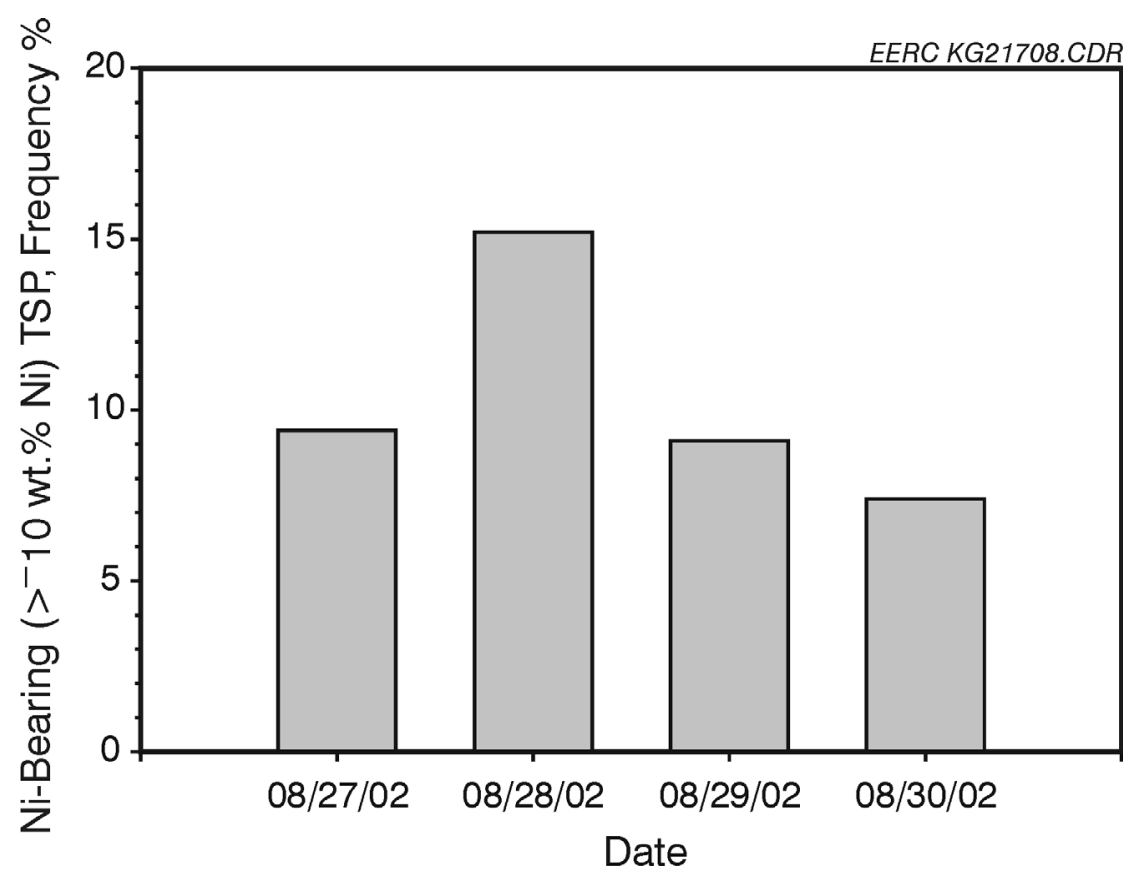

Figure 19. Number concentrations of Ni-bearing ( $\geq 10 \mathrm{wt} \%)$ particles in Davie TSP samples.

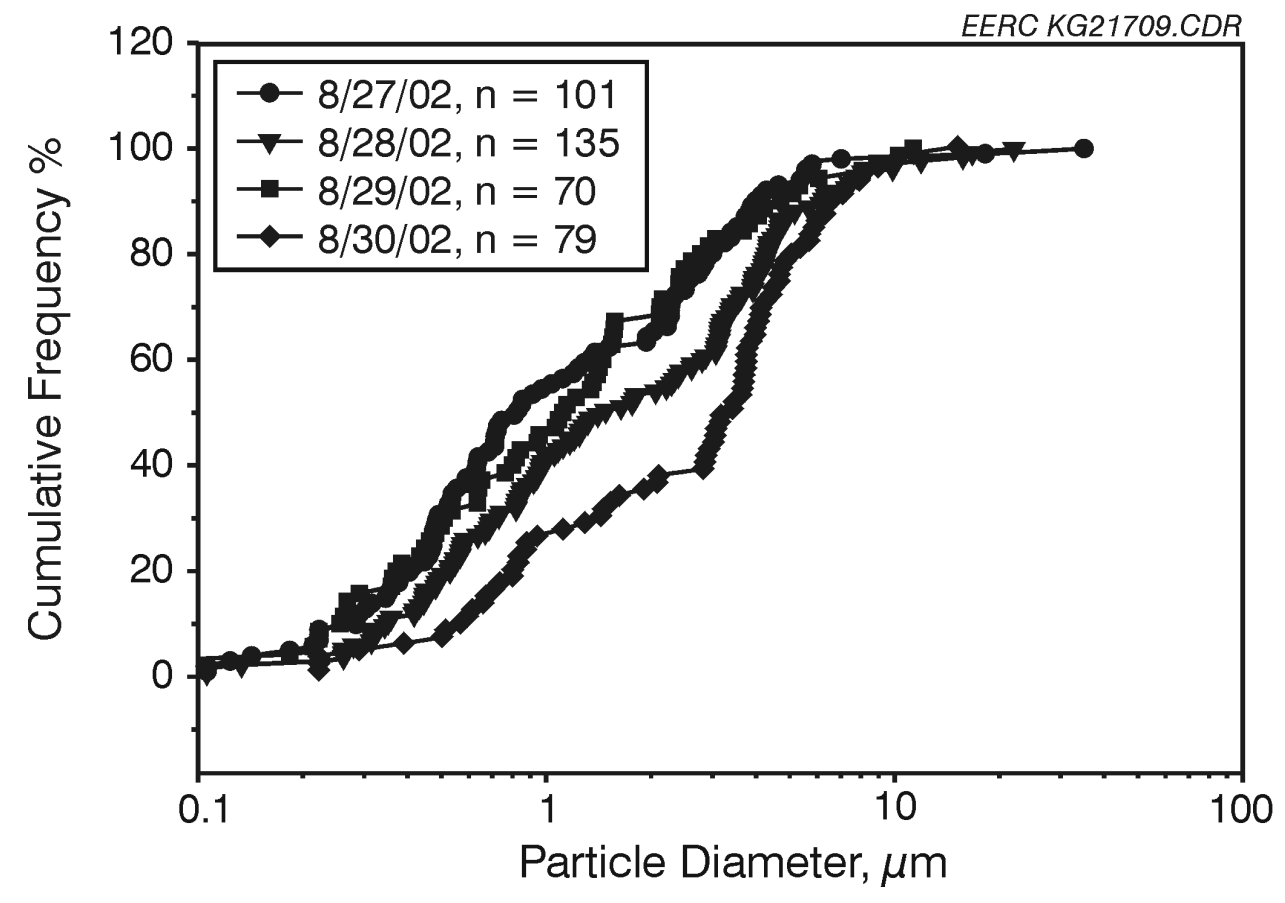

Figure 20. Particle-size distribution of Ni-bearing ( $\geq 10 \mathrm{wt} \%$ ) particles in Davie TSP. 
sources. Ni-bearing particles sampled on August 30 were significantly coarser than those sampled on August 27-29.

\subsection{CONCLUSIONS}

- Chemical mass balance considerations, XRD, and XANES analyses indicated that the soluble Ni extraction procedure (Step I) of Luk et al. ${ }^{18}$ provided a reliable estimate of $\mathrm{NiSO}_{4} \cdot 6 \mathrm{H}_{2} \mathrm{O}$ concentration in a $\mathrm{NiSO}_{4} \cdot 6 \mathrm{H}_{2} \mathrm{O}-\mathrm{Ni}_{3} \mathrm{~S}_{2}-\mathrm{Ni}^{0}-\mathrm{NiO}$ compound mixture but overestimated $\mathrm{Ni}^{0}$ and underestimated $\mathrm{Ni}_{3} \mathrm{~S}_{2}$ and $\mathrm{NiO}$ concentrations.

- Sulfur K-edge XANES analyses indicated that $>97 \%$ of the total sulfur in Davie, Florida, TSP, $\mathrm{PM}_{10}$, and $\mathrm{PM}_{2.5}$ is present as $\mathrm{SO}_{4}$.

- The airborne Ni concentrations of 2.3 and $1.5 \mathrm{ng} / \mathrm{m}^{3}$ measured for TSP and $\mathrm{PM}_{10}$, respectively, at the Davie, Florida, SLAMS/NAMS site during August 26-31, 2002, is similar to the EPA estimated annual average ambient Ni concentration of $1.9 \mathrm{ng} / \mathrm{m}^{3}$ for Broward County. ${ }^{37}$

- Sequential Ni extraction and XANES results indicated that $\mathrm{NiSO}_{4} \cdot \mathrm{xH}_{2} \mathrm{O}$ and a nickel oxide compound, possibly $\mathrm{NiFe}_{2} \mathrm{O}_{4}$, were the dominant $\mathrm{Ni}$ species occurring in Davie, Florida, TSP. Both methods also indicated that a small proportion of NiS was present.

- XAFS spectroscopy analyses indicated that the sequential Ni extraction procedure of Luk et al. ${ }^{18}$ selectively and quantitatively removed $\mathrm{NiSO}_{4} \cdot \mathrm{xH}_{2} \mathrm{O}$ from Davie, Florida, TSP but overestimated the sulfidic $\mathrm{Ni}$ and $\mathrm{Ni}^{0}$ fractions and underestimated oxidic $\mathrm{Ni}$.

- Davie, Florida, $\mathrm{PM}_{10}$ lacked NiS, but $\mathrm{NiSO}_{4} \cdot \mathrm{xH}_{2} \mathrm{O}$ was more abundant in comparison to TSP, probably because of the greater surface area of $\mathrm{PM}_{10}$ on which $\mathrm{NiSO}_{4} \cdot \mathrm{xH}_{2} \mathrm{O}$ heterogeneously condensed or adsorbed.

- An insufficient amount of $\mathrm{PM}_{2.5}$ was sampled from Davie, Florida, to quantify Ni and perform speciation analyses.

- Approximately $8 \%-15 \%$ of the total number of particles sampled from the Davie, Florida, SLAMS/NAMS site contained significant Ni concentrations, $\geq 10 \mathrm{wt} \%$. Most of these Ni-bearing particles were $<10 \mu \mathrm{m}$ in diameter.

- Direct metal speciation techniques such as XAFS spectroscopy should be used to verify the applicability and reliability of sequential Ni extraction methods before they are employed on a specific sample type (raw materials, workplace dust, ambient air TSP, $\mathrm{PM}_{10}, \mathrm{PM}_{2.5}$, etc.).

- The limitations of sequential Ni extraction methods applied to urban PM samples need to be considered when using such indirect Ni speciation results to assess the potential inhalation health risks associated with individual Ni species. 


\subsection{REFERENCES}

1. Nriagu, J.O. A Global Assessment of Natural Sources of Atmospheric Trace Metals. Nature 1989, 338, 47-49.

2. Mason, B.; Moore, C.B. Principles of Geochemistry, 4th Ed.; John Wiley \& Sons, 1982.

3. Nriagu, J.O. Global Metal Pollution: Poisoning the Bioshpere? Environment 1990, 32 (7), $7-11$ and $28-32$.

4. Locating and Estimating Air Emissions from Sources of Nickel; EPA-450/4-84-007f, U.S. Environmental Protection Agency, Office of Air Quality Planning and Standards: Research Triangle Park, NC, March 1984.

5. Nickel Producers Environmental Research Association (NiPERA). Occupational Exposure Limits Criteria Document for Nickel and Nickel Compounds, Volume 1: Summary, Conclusions, and Recommendations; Prepared for the European Commission, DirectorateGeneral V, Public Health and Safety at Work Directorate. Prepared by NiPERA in collaboration with Eurometaux, Dec 24, 1996.

6. Documentation for the 1996 Base Year National Toxics Inventory for Onroad Sources; U.S. Environmental Protection Agency, Emission Factor and Inventory Group (MD-14), Emissions, Monitoring and Analysis Division: Research Triangle Park, NC, June 2000.

7. Documentation for Aircraft, Commercial Marine Vessel, Locomotive, and Other Nonroad Components of the National Emissions Inventory; U.S. Environmental Protection Agency, Emission Factor and Inventory Group (D205-01), Emissions, Monitoring and Analysis Division: Research Triangle Park, NC, Nov 2002.

8. Lee, Jr., R.E.; von Lehmden, D.J. Trace Metal Pollution in the Environment. JAPCA 1973, $23(10), 853-857$.

9. Schroeder, W.H.; Dobson, M.; Kane, D.M. Toxic Trace Elements Associated with Airborne Particulate Matter: A Review. Air Pollut. Control Assoc. 1987, 11, 1267-1287.

10. Sunderman, Jr., F.W.; Oskarsson, A. Nickel. In Metals and Their Compounds in the Environment: Occurrence, Analysis, and Biological Relevance; Merian, E., Ed.; VCH, Weinheim, 1991; pp 1101-1126.

11. Agency for Toxic Substances and Disease Registry (ATSDR). Toxicology Profile for Nickel; Prepared by Sciences International, Inc., under subcontract to Research Triangle Institute under Contract No. 205-93-0606; U.S. Department of Health and Human Services, Public Health Service: Atlanta, GA, Sept 1997. 
12. Priority Substances List: Supporting Documentation, Health-Related Sections, Nickel and Its Compounds; Health Canada, Canadian Environmental Protection Act: Ottawa, Canada, 1993.

13. Provisions for Attainment and Maintenance of National Ambient Air Quality Standards; U.S. Public Law 101-549, 1990.

14. National Ambient Air Quality Standard for Lead - Final Rules and Proposed Rulemaking. Fed. Regist. 1978, 43 (194), 46246-46277.

15. 1996 Toxics Release Inventory, Public Data Release - Ten Years of Right-to-Know; EPA 745R-08-005; U.S. Environmental Protection Agency, Washington, DC, May 1998.

16. Study of Hazardous Air Pollutant Emissions from Electric Utility Steam Generating Units-Final Report to Congress: Volume 1; EPA-453/R-98-004a; U.S. Environmental Protection Agency: Washington, DC, Feb 1998.

17. Toxicology Excellence for Risk Assessment (TERA). Toxicological Review of Soluble Nickel Salts; Prepared by TERA for the Metal Finishing Association of Southern California, Inc., U.S. Environmental Protection Agency, and Health Canada under subcontract in part with Science Applications International Corporation, EPA Contract No. 68-C7-0011, March 1999.

18. Luk, K.K.; Grohse, P.M.; Gutknecht, W.F. Development of a Method for Speciation of Nickel; Research Triangle Institute Report No. RTI 91C-7454, Oct 2000.

19. Zatka, V.J.; Warner, J.S.; Maskery, D. Chemical Speciation of Nickel in Airborne Dusts: Analytical Method and Results of an Interlaboratory Test Program. Environ. Sci. Technol. 1992, 26, 138-144.

20. Bolt, H.M.; Noldes, C.; Blaszkewicz, M. Fractionation of Nickel Species from Airborne Aerosols: Practical Improvements and Industrial Applications. Int. Arch. Occup. Environ. Health 2000, 73, 156-162.

21. Füchtjohann, L.; Jakubowski, N.; Gladtke, D.; Klockow, D.; Broekaert, J.A.C. Speciation of Nickel in Airborne Particulate Matter by Means of Sequential Extraction in a Micro Flow System and Determination by Graphite Furnace Atomic Absorption Spectrometry and Inductively Coupled Plasma Mass Spectrometry, J. Environ. Monit. 2001, 3, 681-687.

22. Huggins, F.E; Huffman, G.P.; Robertson, J.D. Applications of XAFS Spectroscopy to the Investigation of HAPs Element in Particulate Matter Samples. Prepr. Pap.-Am. Chem. Soc., Div. Environ. Chem. 1998, 38 (2), 143-145.

23. Huggins, F.E.; Shah, N.; Huffman, G.P.; Robertson, J.D. XAFS Spectroscopic Characterization of Elements in Combustion Ash and Fine Particulate Matter. Fuel Process. Technol. 2000, 65-66, 203-218. 
24. Huggins, F.E; Huffman, G.P.; Robertson, J.D. Speciation of Elements in NIST Particulate Matter SRMs 1648 and 1650, J. Hazard. Mater. 2000, 74 (1-2), 1-23.

25. Galbreath, K.C.; Toman, D.L.; Zygarlicke, C.J.; Huggins, F.E.; Huffman, G.P.; Wong, J. Nickel Speciation of Residual Oil Fly Ash and Ambient Particulate Matter Using X-Ray Absorption Spectroscopy. J. Air Waste Manage. Assoc. 2000, 50 (11), 1876-1886.

26. Broward County Planning Services Division. http://gis.broward.org/psd/cni00900.htm (accessed Feb 26, 2003).

27. Compendium of Methods for the Determination of Inorganic Compounds in Ambient Air; EPA/625/R-96/010a; U.S. Environmental Protection Agency: Washington, DC, June 1999.

28. Analysis of Commercial Marine Vessels Emissions and Fuel Consumption Data; EPA420-R00-002; U.S. Environmental Protection Agency, Office of Transportation and Air Quality: Washington, DC, February 2000.

29. About Port Everglades. http://www.broward.org/poi00200.htm (accessed March 11, 2003).

30. American Society for Testing and Materials (ASTM). MethodD 6357 Standard Test Methods for the determination of Trace Elements in Coal, Coke, and Combustion Residues from Coal Utilization Processes by Inductively Coupled Plasma Atomic Emission Spectrometry, Inductively Coupled Plasma Mass Spectrometry, and Graphite Furnace Atomic Absorption Spectrometry, Annual Book ASTM Standards 2002, Vol. 5.06.

31. Stern, E.A.; Heald, S.M. Rev. Sci. Instrum. 1979, 50, 1579-1582.

32. Brown, G.E. Jr.; Calas, G.; Waychunas, G.A.; Petiau, J. In Spectroscopic Methods in Mineralogy and Geology; Hawthorne, F.C., Ed.; Rev. in Mineral. Mineralogical Society of America: Washington, DC, 1988; Vol. 18, pp 431-512.

33. Lee, P.A.; Citrin, P.H.; Eisenberger, P.; Kincaid, B.M. Rev. Mod. Phys. 1981, 53, 769-808.

34. Koningsberger, D.C.; Prins, R. X-Ray Absorption. Principles, Applications, Techniques of EXAFS, SEXAFS, and XANES; J. Wiley \& Sons: New York, 1988.

35. Galbreath, K.C.; Zygarlicke, C.J.; Toman, D.L.; Huggins, F.E.; Huffman, G.P. Nickel and Chromium Speciation of Residual Oil Combustion Ash. Combust. Sci. Tech. 1998, 134 (1-6), 243-262.

36. Galbreath, K.C.; Zygarlicke, C.J.; Huggins, F.E.; Huffman, G.P.; Wong, J. Chemical Speciation of Nickel in Residual Oil Ash. Energy Fuels 1998, 12, 818-822.

37. U.S. Environmental Protection Agency, 1996 National Air Toxics Assessment. http://www.epa.gov/ttn/atw/nata/tablconc.html (accessed April 16, 2003). 
APPENDIX A

\section{SEQUENTIAL NICKEL EXTRACTION RESULTS}




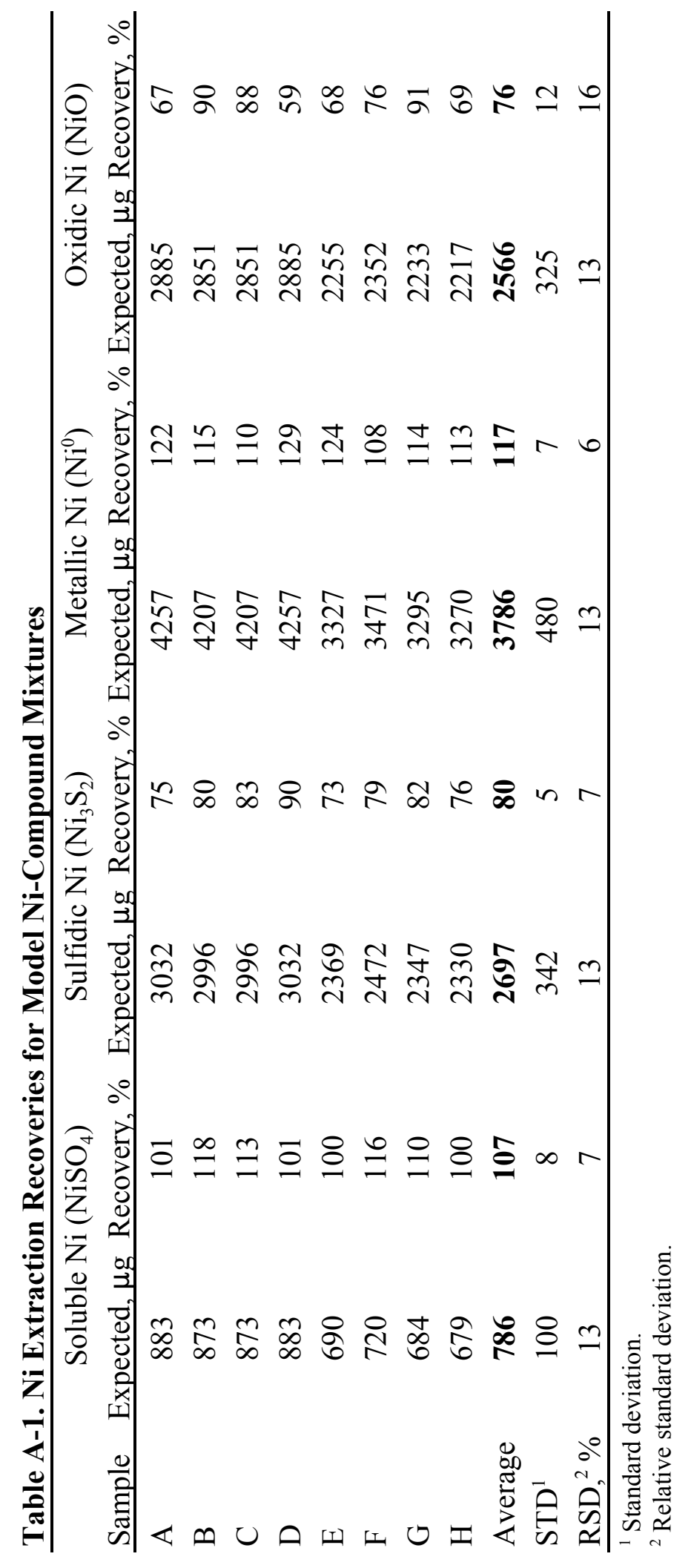




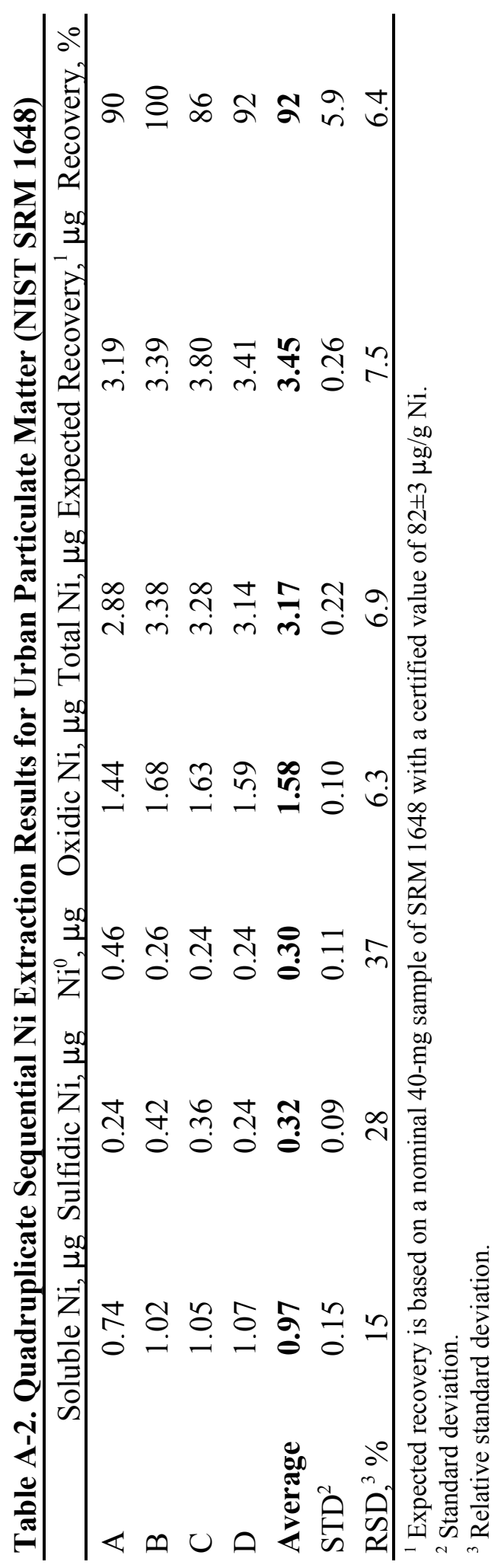


Table A-3. Quadruplicate Sequential Ni Extraction Results for SRM 1648 (Urban Particulate Matter), \% of total Ni

\begin{tabular}{lcccc}
\hline & Soluble Ni & Sulfidic Ni & $\mathrm{Ni}^{0}$ & Oxidic Ni \\
\hline $\mathrm{A}$ & 26 & 12 & 12 & 50 \\
$\mathrm{~B}$ & 30 & 12 & 8 & 50 \\
$\mathrm{C}$ & 32 & 11 & 7 & 50 \\
$\mathrm{D}$ & 34 & 8 & 8 & 51 \\
Average & $\mathbf{3 1}$ & $\mathbf{1 1}$ & $\mathbf{9}$ & $\mathbf{5 0}$ \\
$\mathrm{STD}^{1}$ & 3.4 & 1.9 & 2.2 & 0.5 \\
$\mathrm{RSD}^{2} \%$ & 11 & 18 & 25 & 1.0 \\
\hline
\end{tabular}

${ }^{1}$ Standard deviation.

${ }^{2}$ Relative standard deviation.

Table A-4. Duplicate Sequential Ni Extraction Results for Fort Lauderdale Bulk Urban PM

\begin{tabular}{lcccccc}
\hline Soluble $\mathrm{Ni}, \mu \mathrm{g}$ & Sulfidic $\mathrm{Ni}, \mu \mathrm{g}$ & $\mathrm{Ni}^{0}, \mu \mathrm{g}$ & Oxidic $\mathrm{Ni}, \mu \mathrm{g}$ & Total Ni, $\mu \mathrm{g}$ & Expected total $\mathrm{Ni},{ }^{1} \mu \mathrm{g}$ & Recovery, \% \\
\hline 1.72 & 1.10 & 0.48 & 1.33 & 4.63 & 4.40 & 105 \\
1.70 & 1.12 & 0.55 & 1.37 & 4.74 & 4.40 & 108 \\
\hline
\end{tabular}

Table A-5. Duplicate Sequential Ni Extraction Results for Fort Lauderdale Bulk Urban PM, \% of total Ni

\begin{tabular}{lcccc}
\hline & Soluble Ni & Sulfidic Ni & $\mathrm{Ni}^{0}$ & Oxidic Ni \\
\hline $\mathrm{A}$ & 37 & 24 & 10 & 29 \\
$\mathrm{~B}$ & 36 & 24 & 12 & 29 \\
Average & $\mathbf{3 7}$ & $\mathbf{2 4}$ & $\mathbf{1 1}$ & $\mathbf{2 9}$ \\
$\mathrm{STD}^{1}$ & 0.7 & 0.0 & 1.4 & 0.0 \\
$\mathrm{RSD}^{2} \%$ & 1.9 & 0.0 & 12.9 & 0.0 \\
\hline
\end{tabular}

${ }^{1}$ Standard deviation.

${ }^{2}$ Relative standard deviation. 